\title{
Factors influencing physical activity participation among people living with or beyond cancer: a systematic scoping review
}

\author{
Sarah Elshahat ${ }^{*}$ D, Charlene Treanor and Michael Donnelly
}

\begin{abstract}
Background: It has been posited that physical activity (PA) has the potential to improve health outcomes and the health-related quality of life of people living with or beyond cancer. Despite the well-documented health benefits of PA, there is a low level of PA among cancer patients. A systematic scoping review was conducted to investigate attitudes, perceptions, preferences and barriers vs. facilitators to cancer patients' PA participation.

Methods: A systematic search was performed across four automated databases (PubMed, Embase, PsycINFO and Medline) in keeping with the PRISMA guideline. All cancer types were included, and any age/gender groups were eligible. Both qualitative and quantitative studies were included. The Health Belief Model provided a conceptual framework for the conduct of the scoping review as well as guiding thinking to inform evidence-based interventions.

Results: Ninety-eight articles were included in this review. Nearly half of the studies focused on mixed cancer sites; breast cancer was the most commonly examined cancer type (19\%). Post-treatment was the most commonly investigated stage (33\%), followed by studies of mixed stages of the cancer trajectory (27\%), the acute treatment stage (23\%) and pre-treatment stage (1\%). Patient treatment stage was not reported in 16\% of studies. Cancer patients reported positive attitudes to PA and recognized its benefits for health and wellbeing. Cancer-related side effects (e.g. fatigue) were a leading physiological barrier to PA participation, whereas effective symptom management techniques/tools acted as a powerful facilitator. Psychosocial barriers included low motivation and kinesiophobia, and perceived health benefits and social support/guidance by healthcare providers were significant facilitators. Inaccessible fitness facilities hindered cancer patients' PA engagement though the availability of tailored amenities appeared to be a strong facilitator. PA preferences varied in terms of type, place, time, company and source of information and pointed to the need for individualized PA programs.

Conclusions: There is a need for further research to identify barriers and facilitators to PA that are faced by patients with particular cancer types. Recommended PA promoting-strategies involve including exercise science professionals in healthcare teams and ensuring that fitness facilities are accessible.
\end{abstract}

Keywords: Exercise, Physical activity, Cancer, Health belief model, Barriers, Facilitators

\footnotetext{
* Correspondence: selshahat01@qub.ac.uk

Centre for Public Health, Queen's University Belfast, Institute of Clinical

Sciences, Block B, Royal Victoria Hospital, Belfast BT12 6BA, UK
}

(C) The Author(s). 2021 Open Access This article is licensed under a Creative Commons Attribution 4.0 International License, which permits use, sharing, adaptation, distribution and reproduction in any medium or format, as long as you give appropriate credit to the original author(s) and the source, provide a link to the Creative Commons licence, and indicate if changes were made. The images or other third party material in this article are included in the article's Creative Commons licence, unless indicated otherwise in a credit line to the material. If material is not included in the article's Creative Commons licence and your intended use is not permitted by statutory regulation or exceeds the permitted use, you will need to obtain permission directly from the copyright holder. To view a copy of this licence, visit http://creativecommons.org/licenses/by/4.0/ The Creative Commons Public Domain Dedication waiver (http://creativecommons.org/publicdomain/zero/1.0/) applies to the data made available in this article, unless otherwise stated in a credit line to the data. 


\section{Background}

There is a growing body of evidence on the positive effects of physical activity (PA) engagement on cancer patients' health outcomes, health-related quality of life (HRQoL) and survival rates [1,2]. Cancer is the second major cause of death worldwide, which affected around 15 million of the global population in 2018 [3]. In Europe, cancer accounts for about 1.9 million annual deaths, $9 \%$ of which occurs in the UK $[4,5]$. Furthermore, approximately 0.6 million Americans died of cancer in 2019 [6]. Sufficient PA engagement (i.e. weekly performance of $\geq 150$ min moderate-intensity PA or $\geq 75$ min vigorous-intensity PA) has been suggested to reduce cancer recurrence and improve HRQoL and survival rates among cancer patients [1]. A longitudinal study of 1432 breast cancer patients in the US showed that adequate PA participation was associated with reduced odds of cancer-specific mortality by 73\% [7]. Similarly, a meta-analysis of six studies revealed that sufficient PA performance significantly reduced breast cancer-related deaths and disease recurrence among women with breast cancer [8]. Furthermore, a Canadian cohort study of 830 prostate cancer patients exhibited that participation in regular adequate post-diagnosis leisure PA significantly decreased cancer-specific and all-cause mortality [9]. Similar findings were also reported for other different cancer types [10-12].

Despite the well-documented benefits of PA for improving cancer patients' health outcomes, adherence to the recommended PA guidelines among cancer patients appears to be poor [13]. For instance, two separate crosssectional studies by Courneya et al. [14] and SpeedAndrews et al. [15] showed that about $70-80 \%$ of cancer survivors in Canada were physically inactive. Likewise, two American cross-sectional surveys of survivors of different cancers revealed a low self-reported adequate PA participation (around 30\%) [16, 17]. A cross-sectional survey by Frikkel et al. [18] also revealed that only $22 \%$ of cancer patients in Germany were physically active. Only $15 \%$ of Australian cancer survivors engaged in sufficient PA compared to $45 \%$ of the general population [19].

This low PA level can in part be explained by potential barriers that minimize/hinder cancer patients' PA engagement. For example, around $75 \%$ of participants in the cross-sectional studies by Fernandez et al. [20] and Romero et al. [21] reported that cancer therapy-related side effects acted as a barrier to PA participation. Furthermore, kinesiophobia was a common barrier to PA engagement among patients of different cancers [22, 23]. Lack of appropriate tailored facilities was also cited as a major barrier among cancer patients in different studies $[24,25]$.

The Health Belief Model (HBM) is a theoretical model that has widely been used in health promotion and disease prevention research to understand and predict individuals' health behaviors, including PA and exercise [26-28]. The HBM proposes that individuals likely adopt a healthy behavior when they perceive their susceptibility to an illness/risk and its seriousness, and believe that the benefits to action outweigh the perceived barriers [29]. Cues to action (i.e. stimulus needed to prompt the adoption of health-related behaviors) and self-efficacy (i.e. confidence in one's ability to adopt the health-related behavior) are two supplementary constructs later added to the HBM to enhance its efficacy [30]. Sheill et al. [31] employed the HBM to explore cancer patients' views towards PA engagement. The study revealed that selfefficacy and perceived barriers, such as cancer-related side effects and inaccessible leisure facilities, were significant predictors of exercise behavior. Sheill et al. [31] concluded that more prompts are needed to increase cancer patients' PA participation. These findings highlight the utility of the HBM in exercise-oncology research in providing a thorough understanding of the predictors of PA behaviors to inform the design of effective interventions.

Despite the importance of understanding the influences that affect cancer patients' PA participation to effectively intervene, limited reviews were conducted in this area and those mainly focused on specific cancer types, particularly breast cancer [32, 33]. A comprehensive understanding of different factors that impact cancer patients' PA engagement across various cancer types is crucial to direct future research and clinical practice. The HBM provided a conceptual framework for the conduct of this scoping review and the examination of the attitudes, preferences and influences that affect PA participation among patients of different cancer types in Western countries, and guiding thinking to inform effective, evidence-based interventions. Specific objectives of this review were to (1) explore cancer patients' attitudes and perceived benefits and risks of PA participation, (2) investigate PA preferences among cancer patients, and (3) explore barriers and facilitators to cancer patients' PA engagement.

\section{Methods}

This study employed a scoping review methodology to examine the range and scope of the available literature on the investigated topic, producing a rigorous synthesis and disseminating the existing evidence to date. The five-stage scoping framework designed by Arksey and O'Malley [34] was employed alongside PRISMA guidelines for scoping reviews to maximize robustness [35].

\section{Research question formulation}

A review question was articulated with a view to scoping broadly the relevant landscape of literature: What are 
the perceptions, attitudes and factors influencing physical activity engagement among cancer patients?

\section{Searching for relevant studies}

A rigorous systematic search strategy was utilized to identify relevant records. Fifty-one search terms reflecting the review's key concepts (cancer, physical activity and perceptions) were employed/combined through Boolean operators AND/OR to search four electronic databases (Embase, PubMed, PsycINFO and Medline) from inception to August 2020 (Additional file 1). The search was restricted to human studies and English language papers. A manual search of the Web, Google Scholar and relevant articles' bibliographies was also implemented.

\section{Study selection}

Studies were included if they examined attitudes, perceptions, PA preferences and/or barriers vs. facilitators to PA engagement among cancer patients. Only studies from the Western world (Europe, North America, Australia and New Zealand) were included in an effort to achieve a balance between reducing heterogeneity while being analytically thorough and pursuing the aims of the review. All cancer types were included, and any age/gender groups were eligible. Both qualitative and quantitative studies were included. Studies examining the impact of PA on cancer patients' HRQoL, disease recurrence and survival rates were excluded. Papers assessing the cost-effectiveness of PA programs for cancer patients were not eligible. These inclusion/exclusion criteria were adopted to screen articles' titles and abstracts as well as to entirely assess any potentially pertinent records (Fig. 1). Disagreements were addressed via frequent discussions between the authors.

\section{Data charting}

An Excel-based data extraction tool was developed specifically for this review to facilitate the extraction of pertinent data from eligible records including authorship, country of study, research design, participants, cancer type and key findings.

\section{Collating, summarizing and reporting the results}

A dual-stage analysis approach was adopted to synthetize the extracted evidence. First, data were subjected to a numerical synthesis to detect research gaps and enhance effective reporting. Second, three prime themes were generated to represent the extracted data in accordance with the review's objectives. The HBM was used to develop a conceptual model that illustrated the main findings in terms of factors that influenced cancer patients' performance and maintenance of PA as a healthy behavior (Fig. 2). The implications of the current review were also addressed in order to enhance the utility of the findings for future research, policy-making and clinical practice.

\section{Results}

\section{Characteristics of the included studies}

In total, 9798 articles were retrieved from the automated database search, in addition to 10 papers found through a manual search. Only 98 articles met eligibility criteria and were included for evidence synthesis (Fig. 1). Breast cancer was the most commonly investigated cancer site (19\%), and $41 \%$ of studies examined mixed cancers (Additional file 2). One-third of studies focused on posttreatment survivors, and mixed treatment stages were examined in $27 \%$. The US was the country where most studies were conducted (25\%), followed by Canada (18\%). Qualitative design was employed in $56 \%$ of the studies, and $38 \%$ used a cross-sectional survey design.

\section{Attitudes and perceived benefits and risks of PA}

This theme involved 54 studies addressing cancer patients' attitudes and perceived benefits and risks of PA participation. These were classified into two subthemes:

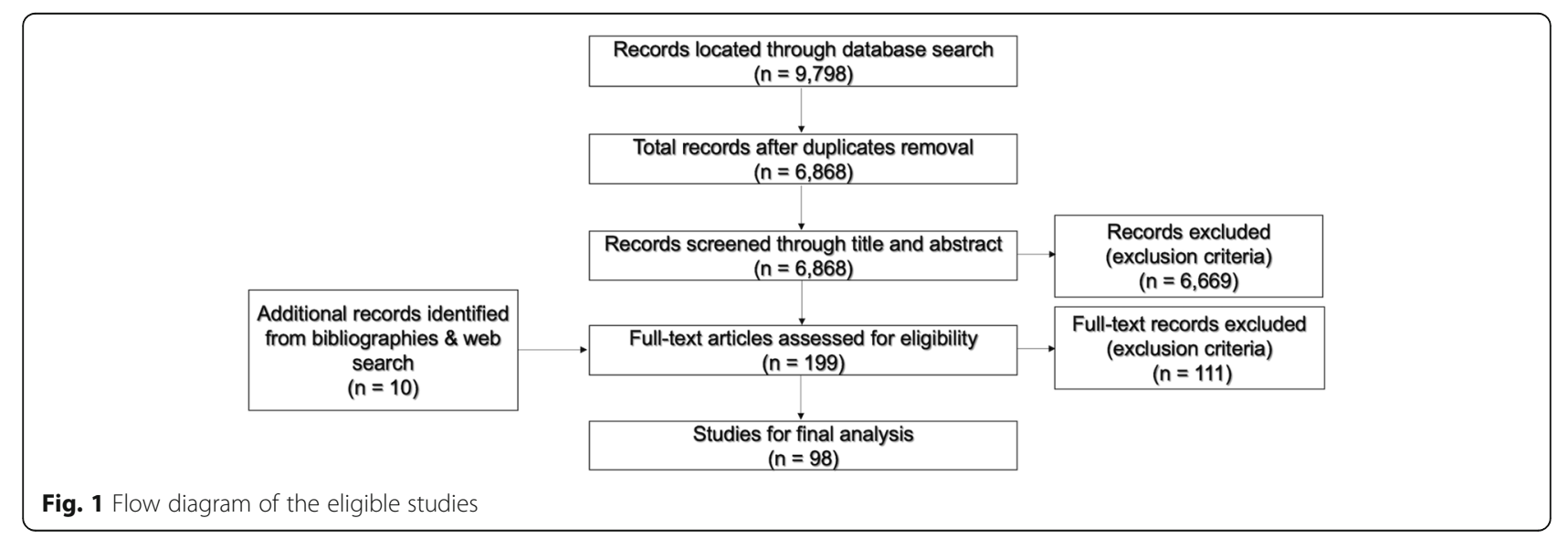




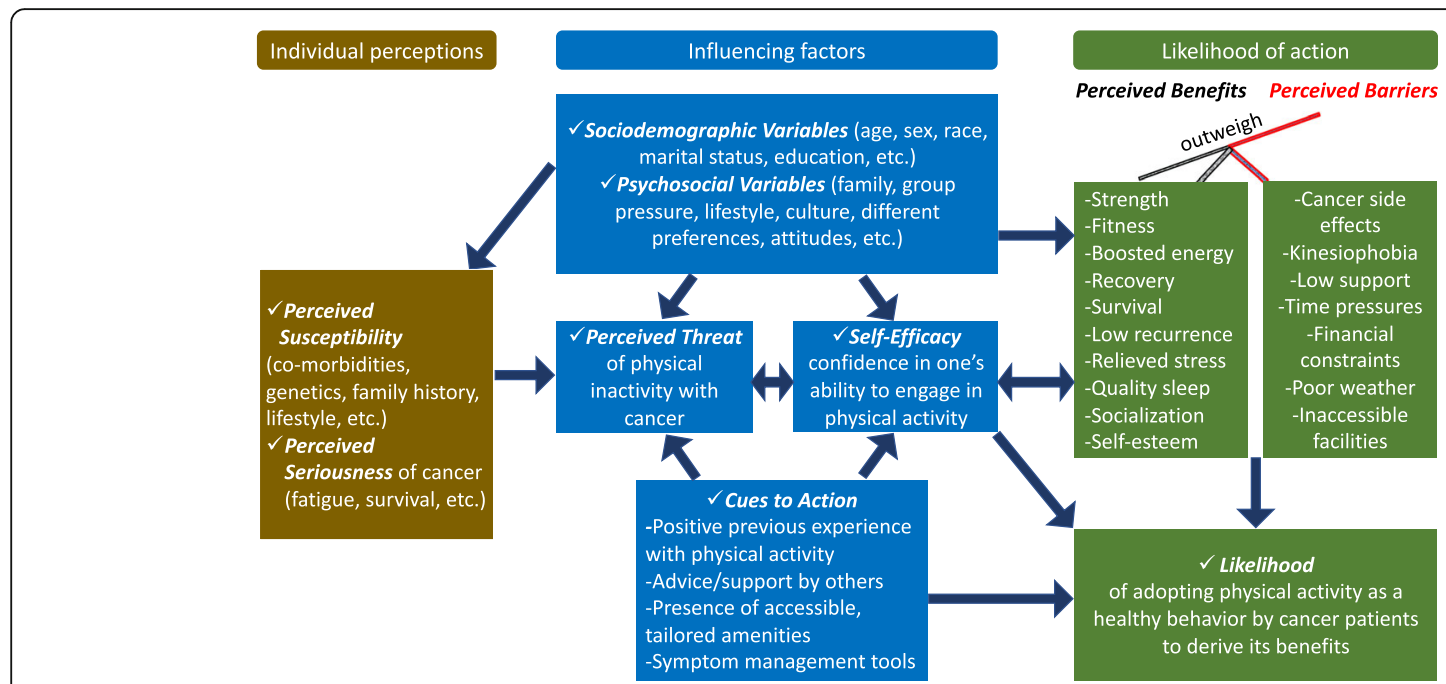

Fig. 2 HBM-based conceptual model showing what predicts PA performance as a healthy behavior by cancer patients

1) attitudes towards PA, and 2) perceived benefits and risks of PA.

\section{Attitudes towards PA}

Across cancer types, patients demonstrated positive attitudes to PA participation, expressing interest and willingness to engage in PA in order to derive its benefits [3641]. For example, about half of participants in two mixed cancer cross-sectional studies by Quain et al. [42] and Blaney et al. [43] reported being interested in exercise opportunities and becoming physically active. Likewise, approximately $70-80 \%$ of mixed cancer participants in five separate quantitative and qualitative studies reported positive attitudes to PA, expressing a desire for PA program opportunities to increase their PA levels [44-48].

\section{Perceived benefits and risks of $P A$}

Cancer patients believed that PA was beneficial for their physical health and mental well-being (Table 1). Promoting health and recovery was the most commonly perceived physiological benefit reported by patients across cancer types and treatment stages in different qualitative studies. Cancer patients perceived that exercise had the potential to minimize cancer-related treatment side effects, particularly fatigue. This perceived health benefit was reported by around $90 \%$ of participants in three cross-sectional studies [43, 55, 71]. Enhancing cardiovascular fitness, boosting energy, improving muscle strength and managing body weight were also notable physiological benefits that were perceived by cancer patients at mixed treatment stages (Table 1). Approximately $90 \%$ of participants in cross-sectional studies by Mizrahi et al. [71] and Rogers et al. [55] believed that PA engagement built up their muscle strength. Across mixed cancer patient participants in qualitative studies, there was a common perception that exercise could prevent disease recurrence and improve their survival. Improved survival was reported as a perceived benefit by nearly $90 \%$ of participants in a mixed cancer cross-sectional study by Eng et al. [22].

Improved state of mind was the most commonly reported perceived psychological benefit of PA participation among patients across cancer types and treatment stages (Table 1). Participants in qualitative studies by Hennessy et al. [82] and Husebø et al. [52] elaborated that PA enhanced their resilience and helped them focus on the positive aspects of life. Cancer patients also perceived that PA alleviated their stress and enhanced quality sleep. Around $85 \%$ of breast cancer patients in a cross-sectional study by Rogers et al. [55] believed that exercise reduced their psychological distress levels. Across cancer types, group exercising was perceived to reduce their isolation by providing socialization opportunities. Improved self-esteem and confidence in oneself were also among the perceived psychological benefits of PA.

Mixed cancer patients at different treatment stages perceived PA participation to be associated with increased risk of fatigue and exhaustion (Table 1). This perceived risk was reported by around $50 \%$ of lung cancer patient participants in a cross-sectional survey by Karvinen et al. [65]. Qualitative studies showed that pain and injury were also common perceived risks recognized by patients across cancer types. Risk of pain was reported by about $30 \%$ of lung and breast cancer patient participants in cross-sectional studies by Karvinen et al. [65] and Rogers et al. [55].

\section{PA preferences}

Thirty-four studies explored the PA preferences of cancer patients and these were organized into three 


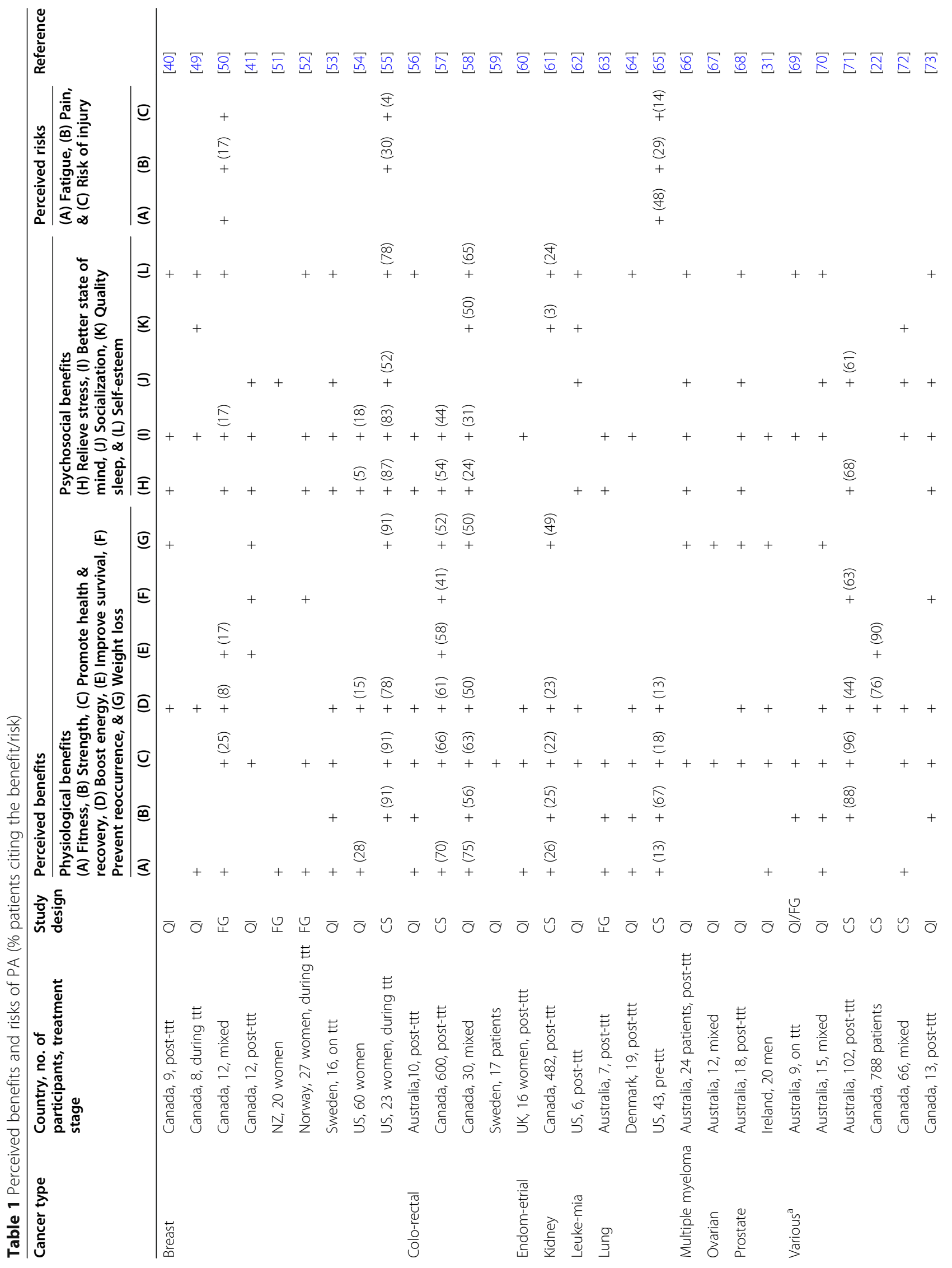




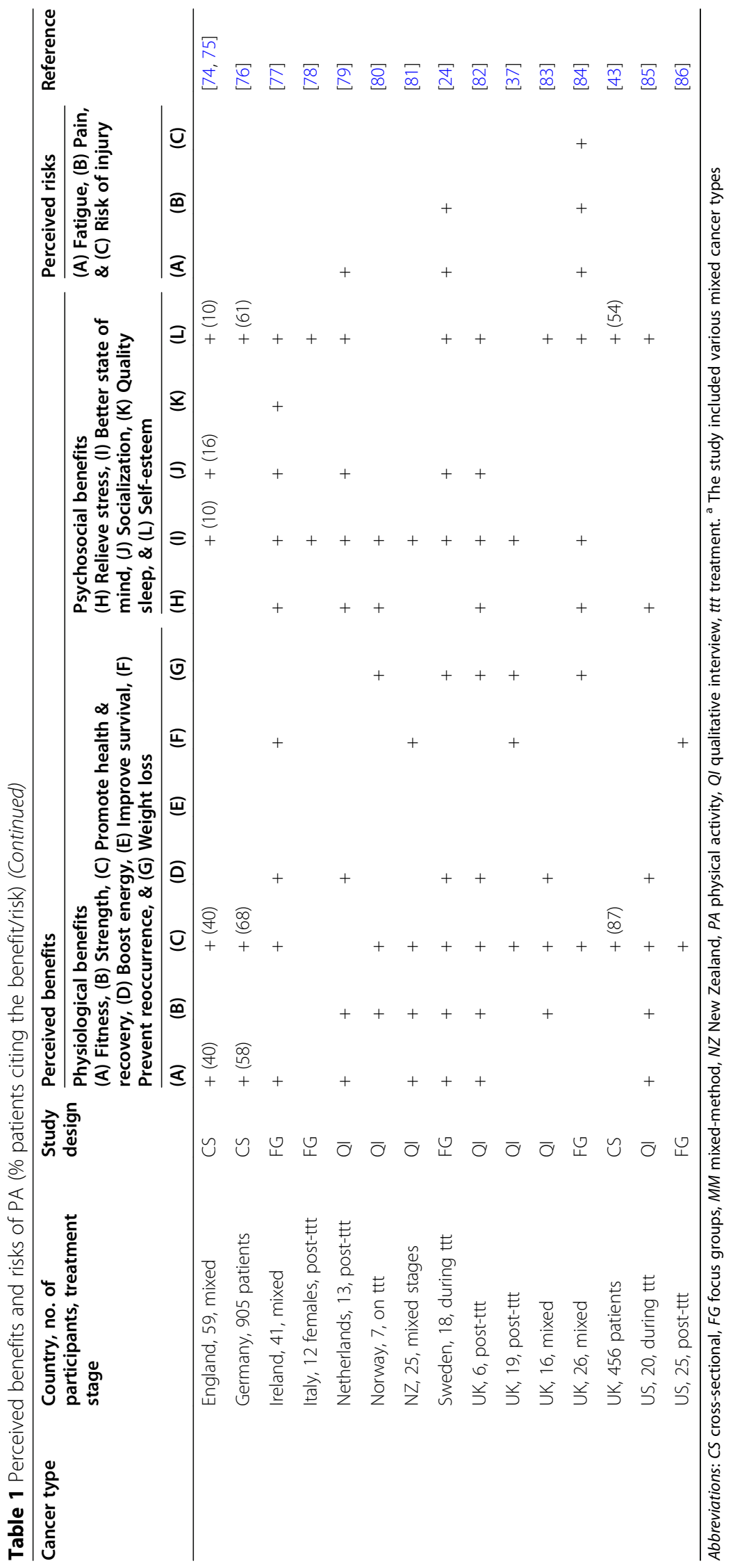


categories: 1) PA types and places for practice, 2) persons to provide information and time to start, and 3) company and time of the day.

\section{PA types and places for practice}

Walking was the most preferred type of PA cited by patients across cancer types during the treatment and post-treatment stages (Table 2). All breast cancer patient participants in a cross-sectional study by Rogers et al. [55] reported that walking was their favourite PA type. Similarly, around $75 \%$ of mixed cancer participants in cross-sectional studies by Blaney et al. [43] and Ross et al. [96] chose walking as their most preferred PA type. Qualitative studies revealed that swimming, cycling and yoga were also popular PA types among mixed cancer patients. Approximately, $60-70 \%$ of participants in cross-sectional studies of mixed cancer by Rogers et al. [55] and Ross et al. [96] identified swimming and cycling as their favourite PA types. Resistance weight and strength training were also commonly reported PA types. In their qualitative and quantitative studies, Owusu et al. [54] and Rogers et al. [55] found that half of breast cancer patient participants preferred resistance weight and strength training during the treatment and post-treatment stages. Other PA type preferences reported by patients across cancer types included gardening, jogging, ball sports, dancing, gymnastics and stretching.

Home and fitness centres were the most preferable places for PA practice among mixed cancer patients at different treatment stages (Table 2). About $80-90 \%$ of participants in three separate qualitative and quantitative studies reported that they would prefer performing PA at home $[44,85,96]$. Outdoor exercising was also a notable favourable option among patients of different cancer types and treatment stages. Finally, hospital setting was preferred by mixed cancer patients who recognized hospitals as the safest place for PA participation at different treatment stages (Table 2).

\section{Persons to provide information and time to start}

Studies showed that oncologists were the most preferable source of information among patients across cancer types, followed by physiotherapists and nurses (Table 3 ). Around $60-80 \%$ of mixed cancer patient participants in three different quantitative and qualitative studies preferred to receive PA information from oncologists [38, $46,85]$. Other preferable sources of PA information included family doctors and personal trainers.

Overall, cancer patients preferred starting PA programs after finishing their cancer treatment (Table 3). For example, about half of participants with different cancers in four quantitative and qualitative studies reported "after treatment" as their most preferred time to start any PA programs $[44,45,89,91]$. On the other hand, cross-sectional studies showed that starting PA programs immediately after cancer diagnosis and during treatment was preferred by about 20 and $10 \%$ of the patients, respectively $[45,89,91]$ (Table 3 ).

\section{Company and time of the day}

Exercising alone was a commonly reported option by patients across cancer types and treatment stages (Table $3)$. Around half of mixed cancer participants in four cross-sectional studies admitted that they preferred exercising alone $[45,46,87,89]$. On the other hand, about $20 \%$ of participants in a cross-sectional survey by Blaney et al. [43] chose to exercise either with family members or other cancer patients (Table 3).

Studies showed that morning was the favourite time of the day for mixed cancer patients to participate in PA, followed by the afternoon and the evening (Table 3). In their quantitative and qualitative studies, Rogers et al. [55] and Agasi-Idenburg et al. [92] noted that nearly half of participants preferred to engage in $\mathrm{PA}$ in the morning.

\section{Barriers and facilitators to PA participation}

This theme comprised 82 studies addressing 13 barriers and 9 facilitators to PA engagement among cancer patients (Tables 4 and 5). Barriers and facilitators were organized into three main subthemes: 1) physiological factors, 2) psychosocial and cultural factors, and 3) economic and environmental influences.

\section{Physiological factors}

Studies revealed that cancer and its related treatment's side effects acted as a significant physiological barrier to PA participation among patients across cancer types and treatment stages (Table 4). In five cross-sectional studies, about $70-80 \%$ of mixed cancer patient participants at different treatment stages reported that cancer therapy-related adverse effects hindered their PA engagement [18, 20, 21, 25, 48]. The most common and significant side effects reported by mixed cancer patients were fatigue, gastrointestinal issues and joint pain. Other additional adverse effects were site-specific, such as urinary incontinence (prostate cancer), upper-limb movement issues (breast cancer) and feeding tube limitations (head/neck cancer). Qualitative studies showed that the presence of co-morbidities was a major barrier to PA among mixed cancer patients at different treatment stages (Table 4). The most prevalent co-morbidities reported by cancer patients included arthritis, diabetes and heart disease. Cross-sectional studies by Bluethmann et al. [121] and Frikkel et al. [18] showed that comorbidity was a significant negative predictor of PA levels among mixed cancer patients. 


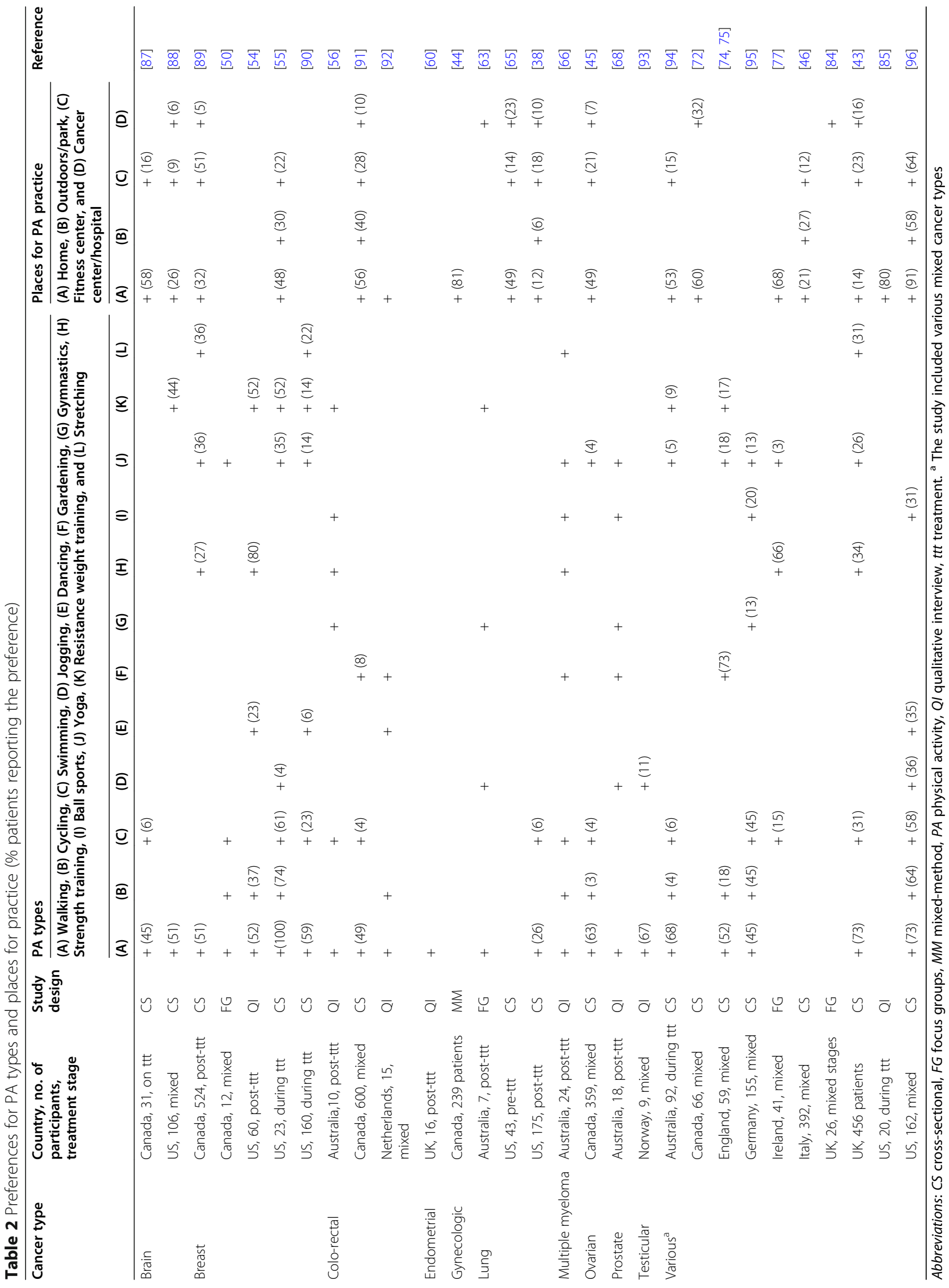




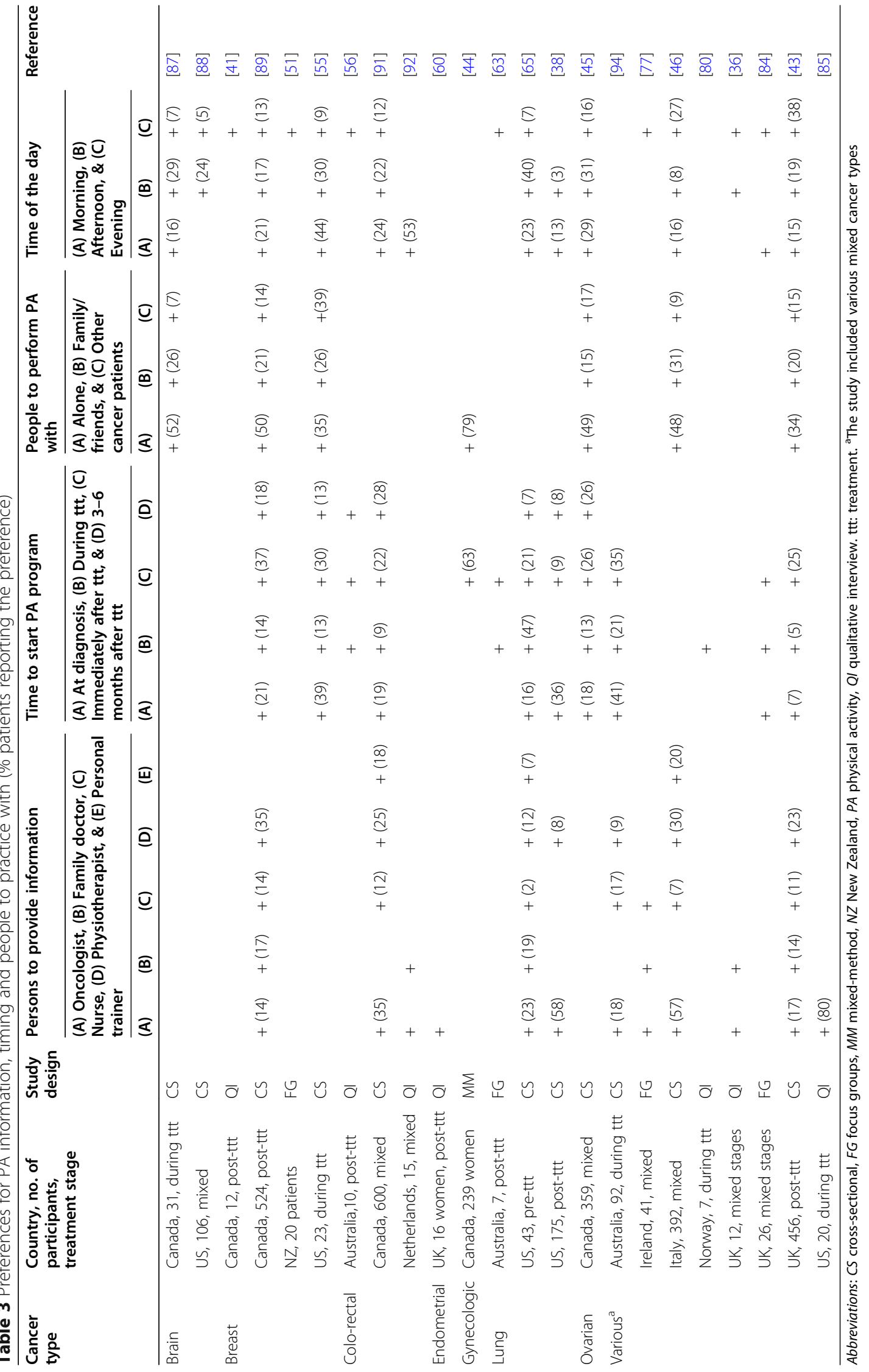




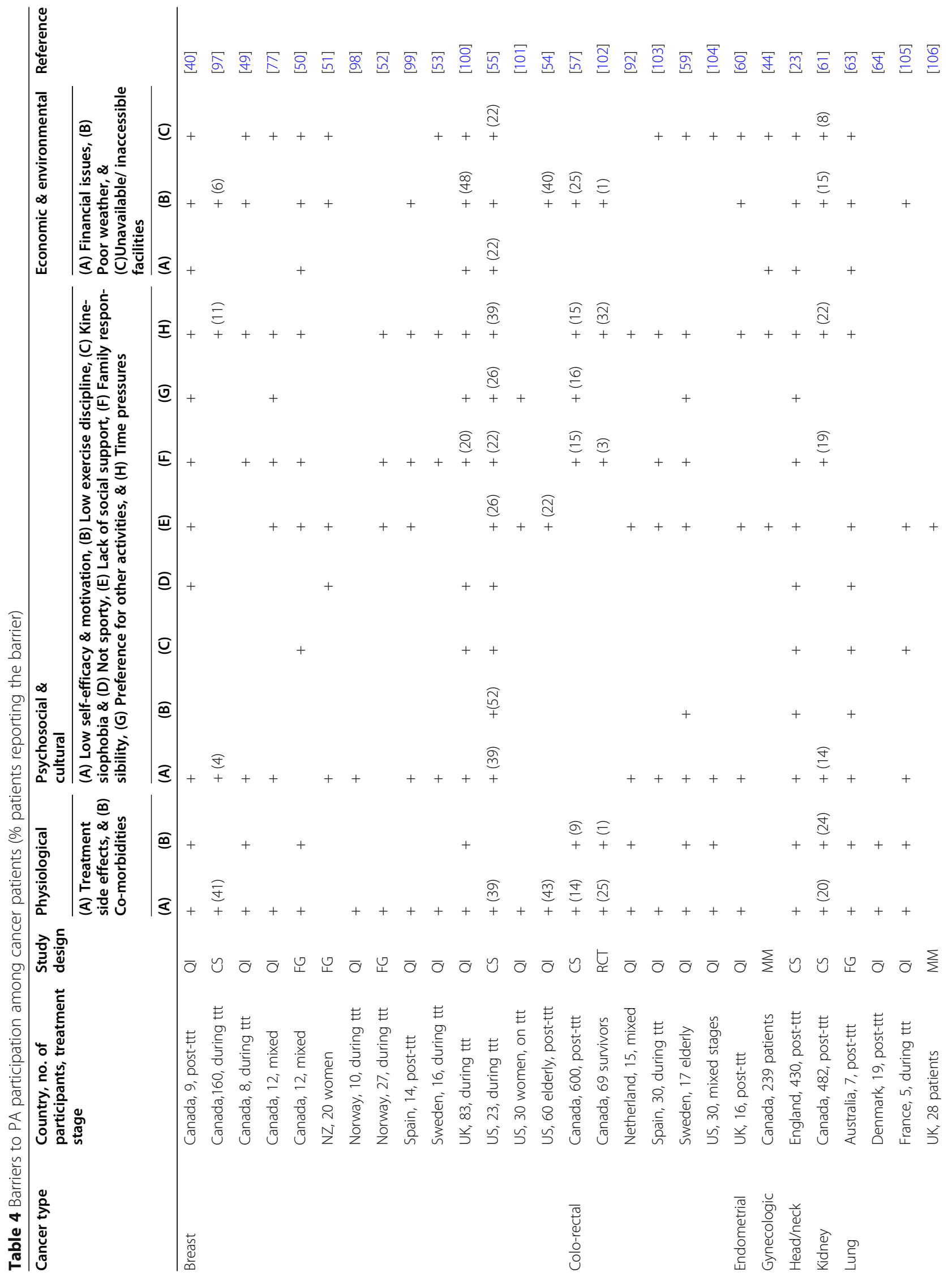




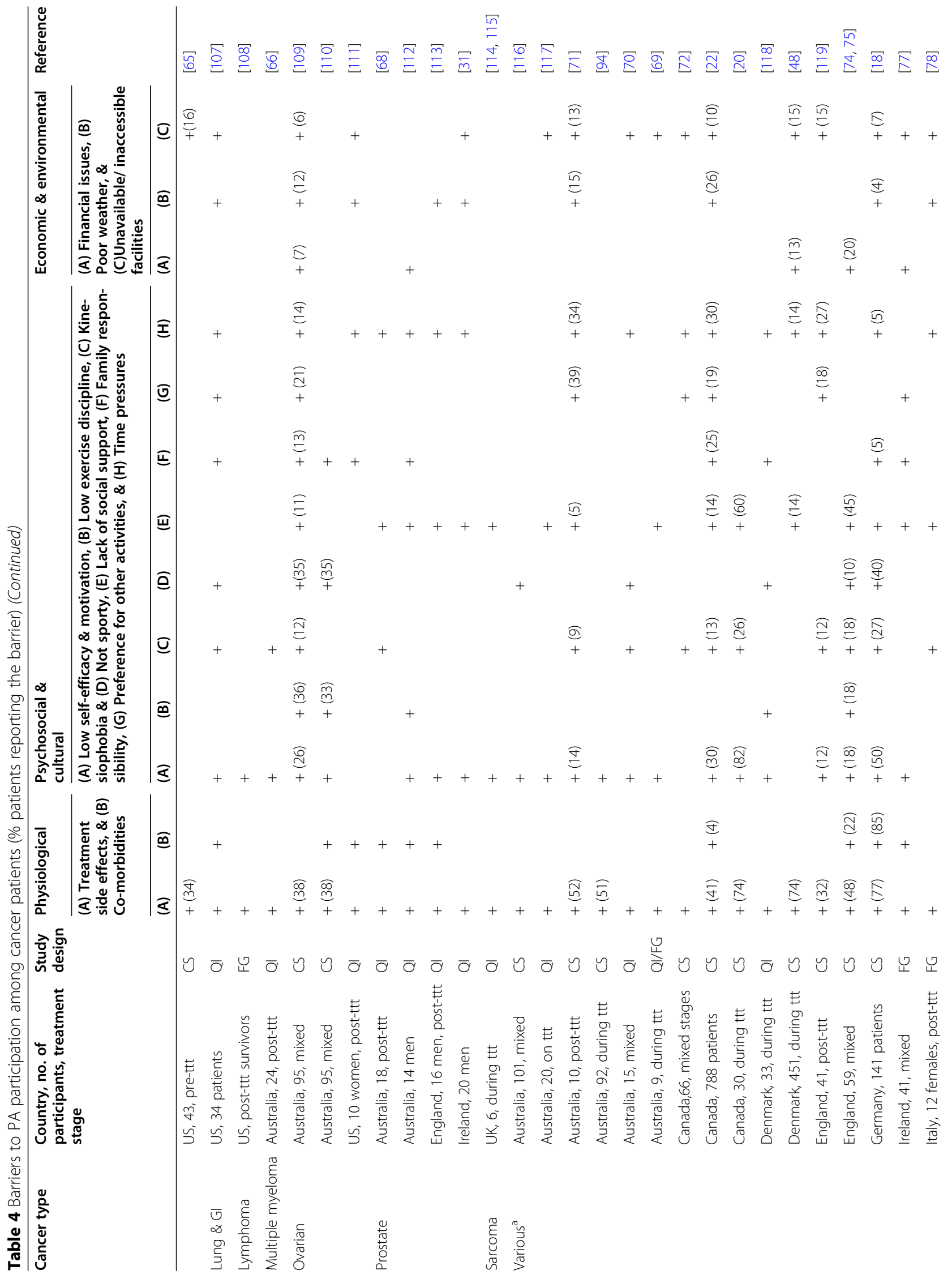




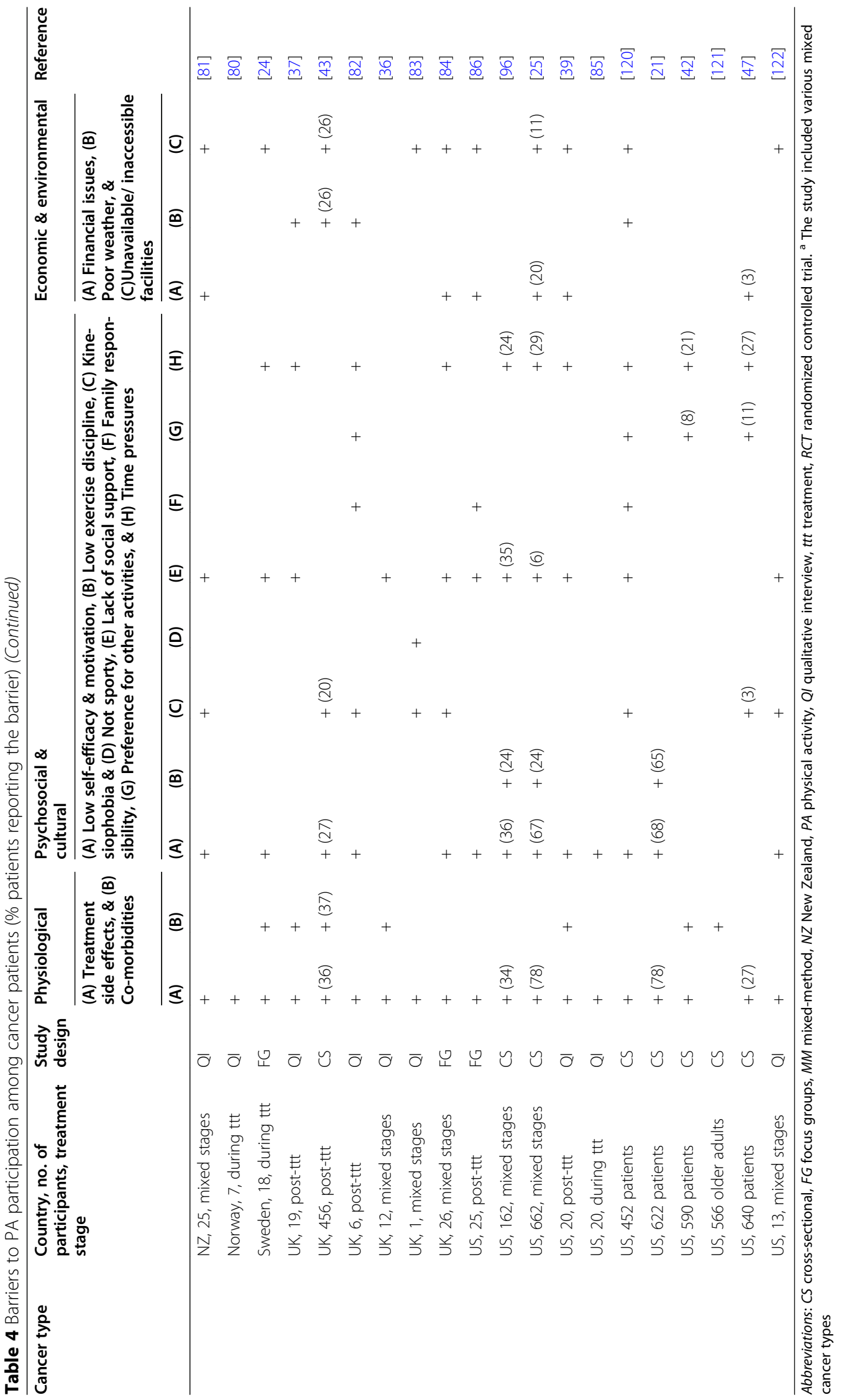


Table 5 Facilitators to PA participation among cancer patients (\% patients reporting the facilitator)

\begin{tabular}{|c|c|c|c|c|c|c|c|c|c|c|c|c|}
\hline \multirow[t]{3}{*}{$\begin{array}{l}\text { Cancer } \\
\text { type }\end{array}$} & \multirow{3}{*}{$\begin{array}{l}\text { Country, no. of } \\
\text { participants, treatment } \\
\text { stage }\end{array}$} & \multirow[t]{3}{*}{$\begin{array}{l}\text { Study } \\
\text { design }\end{array}$} & \multirow{2}{*}{\multicolumn{2}{|c|}{$\begin{array}{l}\text { Physiological } \\
\text { (A) Feeling well, \& } \\
\text { (B) Symptom } \\
\text { management } \\
\text { strategies }\end{array}$}} & \multirow{2}{*}{\multicolumn{5}{|c|}{$\begin{array}{l}\text { Psychosocial \& cultural } \\
\text { (A) Positive previous experience, (B) } \\
\text { Perceived benefits, (C) Exercise in } \\
\text { routine } \\
\text { (D) Social support and guidance, \& } \\
\text { (E)Companionship }\end{array}$}} & \multirow{2}{*}{\multicolumn{2}{|c|}{$\begin{array}{l}\text { Economic \& } \\
\text { environmental } \\
\text { (A) Affordable } \\
\text { programs, \& (B) } \\
\text { Accessible/ } \\
\text { tailored amenities }\end{array}$}} & \multirow[t]{3}{*}{ Reference } \\
\hline & & & & & & & & & & & & \\
\hline & & & $\overline{(A)}$ & (B) & (A) & (B) & (C) & (D) & (E) & (A) & (B) & \\
\hline \multirow[t]{12}{*}{ Breast } & Canada, 9 women, post-ttt & Ql & & & + & + & + & + & + & & + & {$[40]$} \\
\hline & Canada, 8, during ttt & Ql & & + & & + & + & + & + & & + & [49] \\
\hline & Canada, 12, mixed stages & Ql & & & & + & & & + & & & {$[77]$} \\
\hline & New Zealand, 20 women & $\mathrm{FG}$ & & & & & + & + & + & & & [51] \\
\hline & Norway, 27, during ttt & FG & & & & + & & + & + & & & {$[52]$} \\
\hline & Spain, 14 women, post-ttt & Q & & & & + & & + & + & & + & [99] \\
\hline & Sweden, 16 , during $\mathrm{ttt}$ & Ql & & & & & & + & + & & + & {$[53]$} \\
\hline & Sweden, 29, post-ttt & MM & & & & & & + & + & & + & [123] \\
\hline & Sweden, 12 , post-ttt & Ql & & & & + & & & & & & [124] \\
\hline & US, 15 women, post ttt & Q & & & & + & & + & + & & & [125] \\
\hline & US, 60 women, post-ttt & Q & & & & & & $+(50)$ & $+(97)$ & & $+(20)$ & {$[54]$} \\
\hline & US, 30 women, during ttt & Q & & & & & & + & & & + & [101] \\
\hline \multirow[t]{3}{*}{ Colo-rectal } & Canada, 600, post-ttt & CS & $+(10)$ & & & & & & $+(13)$ & & $+(12)$ & {$[57]$} \\
\hline & Netherlands, 15, mixed & Q & + & & & + & + & + & + & + & + & {$[92]$} \\
\hline & Sweden, 17 patients & Ql & + & + & & + & & + & & & + & {$[59]$} \\
\hline Endometrial & UK, 16 women, post-ttt & Ql & & & & + & & + & + & & & {$[60]$} \\
\hline Gynecologic & Canada, 239 survivors & $\mathrm{MM}$ & & & & $+(50)$ & & $+(50)$ & + & + & + & {$[44]$} \\
\hline Kidney & Canada, 482, post-ttt & CS & & & & & & & $+(47)$ & & $+(7)$ & {$[61]$} \\
\hline \multirow[t]{4}{*}{ Lung } & Australia, 7, post-ttt & $\mathrm{FG}$ & & & + & & & + & + & & + & {$[63]$} \\
\hline & Denmark, 19, post-ttt & Q & & & & + & + & + & & & + & {$[64]$} \\
\hline & France, 5 patients & Q & & & & + & & + & + & & & [105] \\
\hline & US, 43, during ttt & CS & $+(15)$ & & & & $+(11)$ & $+(15)$ & & & $+(37)$ & {$[65]$} \\
\hline Lung \& Gl & US, 34 patients & Q & & & + & + & + & + & + & & & [107] \\
\hline Lymphoma & US, N/A, post-ttt & FG & & & & & & + & & & + & [108] \\
\hline \multirow[t]{4}{*}{ Prostate } & Australia, 18 men, post-ttt & Q & & & & & & + & + & & & {$[68]$} \\
\hline & Australia, 14 men & Ql & & + & & & & + & + & & & [112] \\
\hline & England, 16 men, post-ttt & Q & & + & & + & & + & + & & + & [113] \\
\hline & Ireland, 20 men & Ql & & & & & & + & & & & {$[31]$} \\
\hline \multirow[t]{11}{*}{ Various $^{a}$} & Australia, 15, mixed stages & Q & & & & + & & + & + & & & [70] \\
\hline & Australia, 9, during ttt & $\mathrm{Q} / / \mathrm{FG}$ & & & & & + & + & & + & + & {$[69]$} \\
\hline & Australia, 102, post-ttt & CS & & & + & $+(99)$ & & $+(97)$ & $+(81)$ & & + & {$[71]$} \\
\hline & Australia, 20, during ttt & Q & & & & & & + & & & + & {$[117]$} \\
\hline & Canada, 30, during ttt & CS & & & $+(63)$ & $+(37)$ & + & $+(32)$ & + & & $+(42)$ & {$[20]$} \\
\hline & Denmark, 33, during ttt & Ql & & + & & + & + & + & + & & & [118] \\
\hline & Germany, 905 patients & CS & & & & + & + & & + & & & {$[76]$} \\
\hline & Ireland, 41, mixed stages & FG & & & & & & + & + & & + & {$[77]$} \\
\hline & Italy, 12, post-ttt & FG & & & + & + & + & + & + & & + & {$[78]$} \\
\hline & New Zealand, 25, mixed & Ql & & & & & & + & + & & + & {$[81]$} \\
\hline & Sweden, 18 , during ttt & $\mathrm{FG}$ & & + & + & & & + & + & & + & {$[24]$} \\
\hline
\end{tabular}


Table 5 Facilitators to PA participation among cancer patients (\% patients reporting the facilitator) (Continued)

\begin{tabular}{|c|c|c|c|c|c|c|c|c|c|c|c|c|}
\hline \multirow[t]{3}{*}{$\begin{array}{l}\text { Cancer } \\
\text { type }\end{array}$} & \multirow{3}{*}{$\begin{array}{l}\text { Country, no. of } \\
\text { participants, treatment } \\
\text { stage }\end{array}$} & \multirow{3}{*}{$\begin{array}{l}\text { Study } \\
\text { design }\end{array}$} & \multirow{2}{*}{\multicolumn{2}{|c|}{$\begin{array}{l}\text { Physiological } \\
\text { (A) Feeling well, \& } \\
\text { (B) Symptom } \\
\text { management } \\
\text { strategies }\end{array}$}} & \multirow{2}{*}{\multicolumn{5}{|c|}{$\begin{array}{l}\text { Psychosocial \& cultural } \\
\text { (A) Positive previous experience, (B) } \\
\text { Perceived benefits, (C) Exercise in } \\
\text { routine } \\
\text { (D) Social support and guidance, \& } \\
\text { (E)Companionship }\end{array}$}} & \multirow{2}{*}{\multicolumn{2}{|c|}{$\begin{array}{l}\text { Economic \& } \\
\text { environmental } \\
\text { (A) Affordable } \\
\text { programs, \& (B) } \\
\text { Accessible/ } \\
\text { tailored amenities }\end{array}$}} & \multirow[t]{3}{*}{ Reference } \\
\hline & & & & & & & & & & & & \\
\hline & & & (A) & (B) & (A) & (B) & (C) & (D) & (E) & (A) & (B) & \\
\hline & UK, 26, mixed stages & $\mathrm{FG}$ & & & & + & + & + & + & & + & [84] \\
\hline & UK, 456, post-ttt & CS & & + & & & & + & + & & + & {$[43]$} \\
\hline & UK, 19 patients, post-ttt & Q & & & & & & + & + & & + & {$[37]$} \\
\hline & UK, 12 , mixed stages & Ql & & + & & & & + & + & & & {$[36]$} \\
\hline & UK, 16, mixed stages & Q & & & & & & + & & & + & {$[83]$} \\
\hline & US, 25, post-ttt & $\mathrm{FG}$ & & & & + & + & + & + & & + & {$[86]$} \\
\hline & US, 20, post-ttt & Q & & & & & & + & + & + & + & [39] \\
\hline & US, 13 , mixed stages & Ql & & & & + & & + & & & + & {$[122]$} \\
\hline
\end{tabular}

Abbreviations: CS cross-sectional, FG focus groups, MM mixed-method, N/A non-available, PA physical activity, Q/ qualitative interview, ttt treatment. ${ }^{\text {a }}$ The study included various mixed cancer types

On the other hand, cancer patients in different quantitative and qualitative studies reported that feeling well (i.e. having no physical symptoms and pain) facilitated their PA participation (Table 5). The presence of effective cancer symptom management strategies was a significant facilitator to PA participation among patients across cancer types and treatment stages. For example, mixed cancer patients in qualitative studies by Karlsson et al. [59] and Swan et al. [36] explained that the presence of tools/products that help minimize pain during exercising (e.g. TheraBand) would help enhance their PA participation. Furthermore, prostate cancer patients in a qualitative study by Hackshaw-McGeagh et al. [113] narrated that the availability of well-fitting, comfortable pads would enable them to engage in PA by managing urinary incontinence issues.

\section{Psychosocial and cultural factors}

Quantitative and qualitative studies showed that low self-efficacy and motivation and limited exercise discipline were common barriers to PA engagement among cancer patients across treatment stages (Table 4). About $70-80 \%$ of mixed cancer participants in cross-sectional studies by Fernandez et al. [20], Romero et al. [21, 25] and Frikkel et al. [18] reported that lack of motivation limited their PA participation. Cancer patients linked their low motivation to feelings of embarrassment and concerns about appearance when exercising in public. Kinesiophobia was a major barrier to PA engagement among cancer patients who were concerned about fall and injury. Cancer patients, moreover, cited "never been active" and "being not sporty" as common barriers to PA participation. In their cross-sectional study, Frikkel et al. [18] noted that not being active prior to diagnosis was a significant positive predictor of physical inactivity among cancer patients. Lack of social support was a key barrier to PA participation among patients across cancer types in separate quantitative and qualitative studies (Table 4). Cancer patients delineated that discouragement by family members and limited support/guidance by clinicians impeded their PA engagement $[69,103]$. Family responsibility was a significant barrier to PA participation among cancer patients, particularly women who prioritized their family/children over self. Cancer patients preferred spending their free time with families, coengaging in social activities rather than exercising [101]. Qualitative and quantitative studies revealed that time pressure was a common barrier to PA engagement. Mixed cancer patients explained that work commitments and cancer-related medical appointments minimized time available for exercising [52, 63, 100].

Qualitative and quantitative studies exhibited that perceived health benefits and positive previous experiences with exercise (exercise-related improvement in cancer symptoms) were strong facilitators to PA participation (Table 5). A cross-sectional study by Mizrahi et al. [71] revealed that $99 \%$ of the cancer patient participants found perceived health benefits to be useful for enhancing their PA participation. Furthermore, having exercise in one's routine facilitated PA engagement among cancer patients. Mixed cancer qualitative and quantitative studies showed that social support was a powerful facilitator to PA participation during and post-treatment stages (Table 5). This included having supportive family and friends and helpful/encouraging healthcare professionals that provide sincere guidance on exercise performance. Companionship was a common facilitator reported by patients across cancer types. In their 
qualitative and quantitative studies, Owusu et al. [54] and Mizrahi et al. [71] found that group exercising with significant others and/or other cancer patients who face similar challenges was a major facilitator among $80-95 \%$ of the participants.

\section{Economic and environmental factors}

Financial issues represented a major economic barrier to PA participation among patients across cancer types (Table 4). Cancer patients in qualitative and quantitative studies by Hefferon et al. [100] and Catt et al. [74] explained that not affording gym memberships hindered their PA participation. Poor weather was a common barrier to PA engagement among cancer patients. Qualitative and quantitative exercise-oncology research showed that inaccessible facilities represented a significant barrier to PA participation among cancer patients across cancer types and treatment stages. Cancer patients detailed that lack of disabled-friendly spaces (e.g. privacy in changing rooms), limited availability of cancer-specific exercise services and inaccessible parking areas hindered their PA engagement $[24,51,72,77,86,100]$.

Qualitative studies showed that availability of affordable PA programs was a common facilitator to PA participation among cancer patients (Table 5). The presence of accessible, tailored amenities was cited as a significant facilitator to PA participation in different quantitative and qualitative studies. Mixed cancer patients reported that the availability of facilities with tailored and individualized PA programs would enable them to be physically active $[83,84,122]$.

\section{Discussion}

This scoping review examined attitudes, perceptions, preferences and barriers vs. facilitators to PA participation among cancer patients to direct future research and inform the development of tailored PA programs. Nearly half of studies investigated mixed cancers, and breast cancer was the most commonly examined cancer type (19\%), highlighting a research gap in other cancer sites particularly cancers with high incidence and prevalence. For example, in 2018, globally, lung cancer was the most prevalent cancer type $(12.3 \%)$ and the most common cause of cancer death (1.8 million deaths) [3]. This review showed that the US is the lead country in exerciseoncology research. Most studies (96\%) employed either qualitative or cross-sectional quantitative research designs which are appropriate for capturing the views of patients.

The HBM aided the analysis of the results of our review and helped to conceptualize and illustrate predictor variables and influencers of PA participation among cancer patients (Fig. 2). Perhaps unsurprisingly, most if not all patients perceived the seriousness of the disease and felt susceptible and vulnerable though these perceptions tended to be tempered by cancer patients. Patients appeared likely to adopt PA as a healthy behavior when they believed that the benefits associated with PA outweighed any perceived barriers, particularly when a patient felt self-efficacious and there were positive cues to PA engagement and even more so when physical inactivity was a perceived threat to recovery. According to our model-guided analysis, the likelihood of cancer patients engaging in physical activity is not a simple linear or sequential process - a set of reciprocal relationships appear to exist between self-efficacy, perceived threat, perceived barriers and benefits; and sociodemographic and psychosocial variables individually and collectively exert influences on this set of relationships and on the likelihood of PA engagement by cancer patients.

Our study demonstrated that most cancer patients showed positive attitudes to PA and were motivated to enhance their PA levels, however, they faced numerous barriers that hindered their PA participation. Providing effective cues to action (e.g. inspiring stories of patients who adopted PA behaviors) may help address any negative or neutral attitudes towards PA among cancer patients [31]. Cancer and its related treatment's side effects acted as a physiological barrier to PA among patients across cancer types. Fatigue is a common symptom among cancer patients described as a feeling of exhaustion that often limits cancer patients' ability to participate in PA [126]. Cancer-related fatigue can be attributed to different factors, including fatiguetriggering cancer-related cytokines and the destruction of healthy cells by cancer treatment. PA has been suggested to help combat fatigue among cancer patients [69]. A Cochrane review of exercise interventions for managing cancer-related fatigue found evidence that exercise/PA was effective during and after cancer treatment [127]. Our review showed that perceived health benefits of PA for fatigue management encouraged cancer patients to participate in PA.

Low motivation owing to self-consciousness about appearance limited cancer patients' PA participation. Cancer patients may have concerns about being judged or getting their appearance criticized by others when exercising [86]. The availability of group exercise opportunities with other cancer patients appeared to help address the low motivation barrier, fostering cancer patients' PA participation. Exercising with other cancer patients can help elicit a sense of comfort/belonging, allowing for peer support and enhancing cancer patients' motivation to participate in PA [92]. One significant psychosocial barrier revealed in this review was low social support and encouragement by significant others and healthcare professionals who provided limited PA advice and guidance. The main focus on therapeutic treatment and 
discharge planning in cancer settings with little attention given to PA education and exercise-based rehabilitation is a common issue in healthcare services in Western countries [103]. Healthcare providers in Europe and the US reported that time pressure in clinics limited their ability to support and guide cancer patients on PA engagement for improving their health outcomes [85, 128]. Given the suggested health benefits of PA for improving cancer patients' health outcomes and survival, exercise education and rehabilitation should be an integral part of cancer services.

Inaccessibility of exercise facilities was a significant environmental barrier to cancer patients' PA participation. Indeed, inaccessible fitness facilities is a major issue that hinders PA engagement among people with disabilities [129]. A study by Rimmer et al. [130] utilized the Accessibility Instrument Measuring Fitness and Recreation Environments tool to assess the accessibility of 227 fitness facilities in 10 American states based on 15 varied criteria, including access routes, parking, professional support and policy. Rimmer et al. [130] noted that most fitness facilities exhibited low accessibility scores across the 15 investigated criteria, revealing a pressing need for improving fitness facilities' accessibility to enhance PA participation among people with disabilities. Similar findings were reported in a systematic review of 14 studies by Cadler et al. [131]. The availability of accessible/ tailored amenities appeared to be a significant facilitator to cancer patients' PA participation. Our review showed varied PA preferences among cancer patients across the type, place, time, source of information and company domains. For example, while some patients considered home or fitness centers as the most favourable place to exercise, others preferred exercising in hospitals. The preference for exercising outside healthcare settings may in part be explained by a desire to restore a sense of normality, whereas the choice of hospitals as a place to exercise can be attributed to the need for feelings of health safety [89]. These findings highlight the need for individualized PA programs that are designed to best serve each patient's needs.

\section{Strengths and limitations}

This scoping review investigated perceptions, preferences and factors influencing PA participation among patients diagnosed with any cancer types to identify gaps in research. Our review produced a HBM-guided conceptual model that represents the set and pattern of factors that influence cancer patients' uptake of PA behavior. A strength of our review was that it adopted a rigorous systematic search strategy to address its objectives. The results of the qualitative and quantitative study designs 'triangulated' or concurred, overall, thereby adding to the synthesis of the available evidence and adding to the confidence about the believability of the review findings. It is important to note that this review included only English language papers and solely studies from Europe, North America, Australia, and New Zealand which may limit the review's findings in terms of the extent to which they might be transferable to low- and middle-income countries, where resources are constrained and the context, culture, organisation, management and delivery of healthcare are different. This review did not involve a quality appraisal of the included studies, in keeping with scoping review methodology guidelines by Arksey and O'Malley [34], and in order to capture a wide range of types of evidence and study designs and identify gaps in research on the study topic.

\section{Conclusions and recommendations}

Most exercise-oncology research focused on mixed cancer patients, and breast cancer was the most commonly investigated cancer type. Cancer patients exhibited positive attitudes towards PA participation and perceived PA to be beneficial for health and wellbeing. Key barriers to PA engagement among cancer patients included treatmentrelated side effects, low motivation, kinesiophobia, low social support, time pressures and inaccessible fitness facilities, whereas effective symptom management strategies, perceived health benefits, social support and guidance, and availability of tailored amenities were powerful facilitators. PA preferences among cancer patients varied in terms of type, place, time, company and source of information, underscoring the need for personalized PA programs that are developed to best meet patients' needs.

Based on this review's findings, we recommend the implementation of mixed-methods research to provide a robust and comprehensive understanding of perceptions, preferences and factors that influence PA participation among cancer patients. Future mixed cancer research should consider analysis by cancer site, and more cancer type-specific studies should be carried out to identify barriers and facilitators to PA that may be pertinent to particular cancer types. There is a need, too, for RCT designs that will determine cancer-specific side effects and inform effective symptom management strategies and appropriate, individualized PA prescriptions and programs. We recommend employing conceptual models such as the HBM framework in future exerciseoncology research to gain as comprehensive as possible understanding about the complex pattern of relationships between variables that predict or influence the adoption of PA as a healthy behavior by cancer patients and to inform the design of necessarily tailored interventions.

Regarding policy and practice, we recommend some actions for consideration by policymakers and 
commissioners to enable cancer patients to increase their PA participation. These involve the inclusion of exercise science professionals in healthcare professional teams to help develop tailored PA services in canter settings. Furthermore, healthcare providers should be encouraged to provide effective exercise education, including support and guidance on PA engagement, to cancer patients. We also propose the implementation of exercise-based rehabilitation as an integral part of cancer treatment settings. Innovative medical healthcare products and technologies that are mainly designed to help manage cancer-related side effects and enhance cancer patients' PA participation are recommended. Finally, community-based fitness facilities are encouraged to enhance their accessibility to serve as a potential health promotion place for people with disabilities, including cancer [131].

\section{Abbreviations}

HBM: Health belief model; HRQoL: Health-related quality of life; PA: Physical activity

\section{Supplementary Information}

The online version contains supplementary material available at https://doi. org/10.1186/s12966-021-01116-9.

Additional file 1. The concepts and search terms run in the automated databases.

Additional file 2. Characteristics of the 98 included studies.

\section{Acknowledgements}

Not applicable

\section{Authors' contributions}

SE, CT and MD conceptualized the study and developed search strategy. SE conducted the database search. SE and CT worked on article screening and data extraction. SE curated and analyzed the data. MD supervised the study processes. SE wrote the original draft, and MD assisted with writing and reviewing/editing the manuscript. All authors approved the final manuscript.

\section{Funding}

MD was part funded by the Medical Research Council (MRC) UK - Newton Fund and the MRC UKRI GCRF during the analysis and writing of this paper.

\section{Availability of data and materials}

All data analyzed in this review are presented in the published article and its additional files 1 and 2 .

\section{Declarations}

Ethics approval and consent to participate

Not applicable.

\section{Consent for publication}

Not applicable.

\section{Competing interests}

The authors declare that they have no competing interests.
Received: 5 January 2021 Accepted: 19 March 2021

Published online: 06 April 2021

\section{References}

1. Angeline G, Passildas J, Gadea E, Abrial C, Molnar I, Trésorier R, et al. Treatment-induced cardiotoxicity in breast cancer: a review of the interest of practicing a physical activity. Oncology. 2019;96(5):1-12. https://doi.org/1 $0.1159 / 000499383$

2. Kapila AK, Hamdi M, Patel A. Clinicians should actively promote exercise in survivors of breast cancer. Clin Breast Cancer. 2018;18(5):e747-9. https://doi. org/10.1016/j.clbc.2018.06.008.

3. WHO. Cancer. https://www.who.int/news-room/fact-sheets/detail/cancer. (2018) Accessed 20 October 2020.

4. WHO. Data and statistics. https://www.euro.who.int/en/health-topics/ noncommunicable-diseases/cancer/data-and-statistics\#: :text=With more than 3.7 million,death and morbidity in Europe. (2020) Accessed 21 October 2020.

5. Cancer Research UK. Cancer statistics for the UK. https://www.cancerresea rchuk.org/health-professional/cancer-statistics-for-the-uk\#heading-One. (2019) Accessed 20 October 2020.

6. American Cancer Society. Cancer facts \& figures. https://www.cancer.org/ research/cancer-facts-statistics/all-cancer-facts-figures/cancer-facts-figures-2 019.htm|\#: :text=Estimated numbers of new cancer,deaths in the United States. (2019) Accessed 22 October 2020.

7. Bradshaw P, Ibrahim J, Khankari N, Cleveland R, Abrahamson P, Stevens J, et al. Post-diagnosis physical activity and survival after breast cancer diagnosis: the Long Island breast Cancer study. Breast Cancer Res Treat. 2014;145(3):735-42. https://doi.org/10.1007/s10549-014-2966-y.

8. Ibrahim EM, Al-Homaidh A. Physical activity and survival after breast cancer diagnosis: meta-analysis of published studies. Med Oncol. 2011;28(3):753-65. https://doi.org/10.1007/s12032-010-9536-x.

9. Friedenreich CM, Wang Q, Neilson HK, Kopciuk KA, McGregor SE, Courneya KS. Physical activity and survival after prostate cancer. Eur Urol. 2016;70(4): 576-85. https://doi.org/10.1016/j.eururo.2015.12.032.

10. Hanyuda A, Kim SA, Martinez-Fernandez A, Qian ZR, Yamauchi M, Nishihara $R$, et al. Survival benefit of exercise differs by tumor IRS1 expression status in colorectal cancer. Ann Surg Oncol. 2016;23(3):908-17. https://doi.org/10.124 5/s10434-015-4967-4.

11. Nechuta S, Chen WY, Cai H, Poole EM, Kwan ML, Flatt SW, et al. A pooled analysis of post-diagnosis lifestyle factors in association with late estrogenreceptor-positive breast cancer prognosis. Int J Cancer. 2016;138(9):2088-97. https://doi.org/10.1002/ijc.29940.

12. Wiskemann J, Kleindienst N, Kuehl R, Dreger P, Schwerdtfeger R, Bohus M. Effects of physical exercise on survival after allogeneic stem cell transplantation. Int J Cancer. 2015;137(11):2749-56. https://doi.org/10.1002/ ijc.29633.

13. Troeschel A, Leach C, Shuval K, Stein K, Patel A. Physical activity in cancer survivors during "re-entry" following cancer treatment. Prev Chronic Dis. 2018:15. https://doi.org/10.5888/pcd15.170277.

14. Courneya KS, Katzmarzyk PT, Bacon E. Physical activity and obesity in Canadian cancer survivors. Cancer. 2008;112(11):2475-82. https://doi.org/1 0.1002/cncr.23455.

15. Speed-Andrews A, Rhodes R, Blanchard C, Culos-Reed S, Friedenreich C, Bélanger $L$, et al. Medical, demographic and social cognitive correlates of physical activity in a population-based sample of colorectal cancer survivors. Eur J Cancer Care. 2011:21:187-96.

16. Blanchard C, Courneya K, Stein K. Cancer survivors' adherence to lifestyle behavior recommendations and associations with health-related quality of life: results from the American Cancer Society's SCS-II. J Clin Oncol. 2008; 26(13):2198-204. https://doi.org/10.1200/JCO.2007.14.6217.

17. Krok-Schoen JL, Pisegna J, Arthur E, Ridgway E, Stephens C, Rosko AE. Prevalence of lifestyle behaviors and associations with health-related quality of life among older female cancer survivors. Support Care Cancer. 2020. https://doi.org/10.1007/s00520-020-05812-3.

18. Frikkel J, Götte M, Beckmann M, Kasper S, Hense J, Teufel M, et al. Fatigue, barriers to physical activity and predictors for motivation to exercise in advanced Cancer patients. BMC Palliat Care. 2020;19(1):43. https://doi.org/1 0.1186/s12904-020-00542-z.

19. Boyle T, Vallance JK, Ransom EK, Lynch BM. How sedentary and physically active are breast cancer survivors, and which population subgroups have higher or lower levels of these behaviors? Support Care Cancer. 2016;24(5): 2181-90. https://doi.org/10.1007/s00520-015-3011-3. 
20. Fernandez S, Franklin J, Amlani N, DeMilleVille C, Lawson D, Smith-Turchyn J. Physical activity and cancer: a cross-sectional study on the barriers and facilitators to exercise during cancer treatment. Can Oncol Nurs J. 2015; 25(2):37-42. https://doi.org/10.5737/236880762513742.

21. Romero S, Li Q, Mao J. Factors and barriers associated with changes in physical activity after cancer diagnosis. J Clin Oncol. 2017;35(5_suppl):162. https://doi.org/10.1200/JCO.2017.35.5_suppl.162.

22. Eng L, Pringle D, Su J, Shen X, Mahler M, Niu C, et al. Patterns, perceptions, and perceived barriers to physical activity in adult cancer survivors. Support Care Cancer. 2018;26(11):3755-63. https://doi.org/10.1007/s00520-018-4239-5.

23. Rogers SN, Travers A, Lowe D, Levy AR, Midgely AW. Importance of activity and recreation for the quality of life of patients treated for cancer of the head and neck. Br J Oral Maxillofac Surg. 2019;57(2):125-34. https://doi. org/10.1016/j.bjoms.2018.10.001.

24. Henriksson A, Arving C, Johansson B, Igelström H, Nordin K. Perceived barriers to and facilitators of being physically active during adjuvant cancer treatment. Patient Educ Couns. 2016;99(7):1220-6. https://doi.org/10.1016/j. pec.2016.01.019.

25. Romero S, Brown J, Bauml J, Hay J, Li Q, Cohen R, et al. Barriers to physical activity: a study of academic and community cancer survivors with pain. J Cancer Surviv. 2018;12(6):744-52. https://doi.org/10.1007/s11764-018-0711-y.

26. Wu S, Feng X, Sun X. Development and evaluation of the health belief model scale for exercise. Int J Nurs Sci. 2020;7(Suppl 1):S23-30. https://doi. org/10.1016/j.jinss.2020.07.006.

27. Shafieian M, Kazemi A. A randomized trial to promote physical activity during pregnancy based on health belief model. J Educ Health Promot. 2017;6(1):40. https://doi.org/10.4103/jehp.jehp_19_15.

28. Villar OAE-D, Montañez-Alvarado P, Gutiérrez-Vega M, Carrillo-Saucedo IC, Gurrola-Peña GM, Ruvalcaba-Romero NA, et al. Factor structure and internal reliability of an exercise health belief model scale in a Mexican population. BMC Public Health. 2017;17(1):229. https://doi.org/10.1186/s12889-017-4150-x.

29. Rosenstock IM. Historical origins of the health belief model. Health Educ Monogr. 1974;2(4):328-35. https://doi.org/10.1177/109019817400200403.

30. Rosenstock IM, Strecher VJ, Becker MH. Social learning theory and the health belief model. Health Educ Q. 1988;15(2):175-83. https://doi.org/10.11 77/109019818801500203.

31. Sheill G, Guinan E, Neill LO, Hevey D, Hussey J. The views of patients with metastatic prostate cancer towards physical activity: a qualitative exploration. Support Care Cancer. 2018;26(6):1747-54. https://doi.org/10.1 007/s00520-017-4008-x.

32. Livsey L, Lewis K. Breast cancer survivors' perceptions of participating in a supervised exercise intervention: an exploratory review of the literature. Women Health. 2018;58(9):1017-36. https://doi.org/10.1080/03630242.201 7.1372844 .

33. Browall M, Mijwel S, Rundqvist $H$, Wengström $Y$. Physical activity during and after adjuvant treatment for breast cancer: an integrative review of women's experiences. Integr Cancer Ther. 2018;17(1):16-30. https://doi.org/10.1177/1 534735416683807

34. Arksey H, O'Malley L. Scoping studies: towards a methodological framework. Int J Soc Res Methodol Routledge. 2005;8(1):19-32. https://doi.org/10.1 080/1364557032000119616.

35. Tricco AC, Lillie E, Zarin W, O'Brien KK, Colquhoun H, Levac D, et al. PRISMA extension for scoping reviews (PRISMA-SCR): checklist and explanation. Ann Intern Med. 2018;169(7):467-73. https://doi.org/10.7326/M18-0850.

36. Swan F, Chen H, Forbes CC, Johnson MJ, Lind M. Cancer Behavioural nutrition and exercise feasibility trial (CanBenefit); phase I qualitative interview findings. J Geriatr Oncol. 2020. https://doi.org/10.1016/j.jgo.2020. 09.026.

37. Smith L, Croker H, Fisher A, Williams K, Wardle J, Beeken RJ. Cancer survivors' attitudes towards and knowledge of physical activity, sources of information, and barriers and facilitators of engagement: a qualitative study. Eur J Cancer Care. 2017;26(4):e12641. https://doi.org/10.1111/ecc.12641.

38. Philip E, Coups E, Feinstein M, Park B, Wilson D, Ostroff J. Physical activity preferences of early-stage lung cancer survivors. Support Care Cancer. 2013; 22(2): 495-502.

39. Black KZ, Johnson L-S, Samuel-Hodge CD, Gupta L, Sundaresan A, Nicholson WK. Perceived barriers and preferred components for physical activity interventions in African-American survivors of breast or endometrial cancer with type 2 diabetes: the S.U.C.C.E.S.S. framework. Support Care Cancer. 2018;26(1):231-40. https://doi.org/10.1007/s00520-017-3839-9.
40. Brunet J, Taran S, Burke S, Sabiston C. A qualitative exploration of barriers and motivators to physical activity participation in women treated for breast cancer. Disabil Rehabil. 2013;35(24):2038-45. https://doi.org/10.3109/ 09638288.2013.802378.

41. Milosevic E, Brunet J, Campbell K. Exploring tensions within young breast cancer survivors' physical activity, nutrition and weight management beliefs and practices. Disabil Rehabil. 2020;42(5):1-7. https://doi.org/10.1080/096382 88.2018.1506512.

42. Quain K, O'Donnell E, Perez G, Rabin J, Park E, Peppercorn J. Room to move: physical activity and exercise barriers in the cancer clinic. J Clin Oncol. 2017; 35(15_suppl):e21601. https://doi.org/10.1200/JCO.2017.35.15_suppl.e21601.

43. Blaney JM, Lowe-Strong A, Rankin-Watt J, Campbell A, Gracey JH. Cancer survivors' exercise barriers, facilitators and preferences in the context of fatigue, quality of life and physical activity participation: a questionnaire-survey. Psychooncology. 2013;22(1):186-94. https://doi.org/10.1002/pon.2072.

44. Tyrrell A, Keats M, Blanchard C. The physical activity preferences of gynecologic cancer survivors. Oncol Nurs Forum. 2014;41(5):461-9. https:// doi.org/10.1188/14.ONF.461-469.

45. Stevinson C, Capstick V, Schepansky A, Tonkin K, Vallance J, Ladha A, et al. Physical activity preferences of ovarian cancer survivors. Psychooncology. 2009;18(4):422-8. https://doi.org/10.1002/pon.1396.

46. Avancini A, Pala V, Trestini I, Tregnago D, Mariani L, Sieri S, et al. Exercise levels and preferences in cancer patients: a cross-sectional study. Int J Environ Res Public Health. 2020;17(15):5351. https://doi.org/10.3390/ijerph1 7155351.

47. Knowlton S, O'Donnell E, Horick N, Perez G, Park E, Rabin J, et al. Moving forward on all fronts: impact, patterns, and barriers to exercise in cancer survivors and patients living with advanced disease. Support Care Cancer. 2020;28(10):4979-88. https://doi.org/10.1007/s00520-020-05344-w.

48. Midtgaard J, Baadsgaard MT, Møller T, Rasmussen B, Quist M, Andersen C, et al. Self-reported physical activity behaviour; exercise motivation and information among Danish adult cancer patients undergoing chemotherapy. Eur J Oncol Nurs. 2009;13(2):116-21. https://doi.org/10.1016/ j.ejon.2009.01.006

49. Ingram C, Wessel J, Courneya KS. Women's perceptions of home-based exercise performed during adjuvant chemotherapy for breast cancer. Eur J Oncol Nurs. 2010;14(3):238-43. https://doi.org/10.1016/j.ejon.2010.01.027.

50. Rogers L, Matevey C, Hopkins-Price P, Shah P, Dunnington G, Courneya K. Exploring social cognitive theory constructs for promoting exercise among breast cancer patients. Cancer Nurs. 2004;27(6):462-73. https://doi.org/10.1 097/00002820-200411000-00006

51. Jones $L M$, Reinhoudt $L L$, Hilverda F, Rutjes C, Hayes SC. Using the integrative model of behavioral prediction to understand female breast cancer survivors' barriers and facilitators for adherence to a communitybased group-exercise program. Semin Oncol Nurs. 2020;36(5):151071. https://doi.org/10.1016/j.soncn.2020.151071.

52. Husebø AML, Karlsen B, Allan H, Søreide JA, Bru E. Factors perceived to influence exercise adherence in women with breast cancer participating in an exercise programme during adjuvant chemotherapy: a focus group study. J Clin Nurs. 2015;24(3-4):500-10. https://doi.org/10.1111/jocn.12633.

53. Backman M, Brovall M, Sundberg CJ, Wengström Y. Experiencing health physical activity during adjuvant chemotherapy treatment for women with breast cancer. Eur J Oncol Nurs. 2015;21:160-7.

54. Owusu C, Albert E, Nock N, Hergenroeder P, Austin K, Bennet E, et al. Perspective of older African-American and non-Hispanic white breast cancer survivors from diverse socioeconomic backgrounds toward physical activity: a qualitative study. J Geriatr Oncol. 2018;9(3):235-42. https://doi.org/10.101 6/j.jgo.2017.12.003.

55. Rogers LQ, Courneya KS, Shan P, Dunnington G, Hopkins-price P. Exercise stage of change, barriers, expectations, values and preferences among breast cancer patients during treatment: a pilot study. Eur J Cancer Care. 2007;16(1):55-66. https://doi.org/10.1111/j.1365-2354.2006.00705.x.

56. Spence RR, Heesch KC, Brown WJ. Colorectal cancer survivors' exercise experiences and preferences: qualitative findings from an exercise rehabilitation programme immediately after chemotherapy. Eur J Cancer Care. 2011;20(2):257-66. https://doi.org/10.1111/j.1365-2354.2010.01214.x.

57. Speed-Andrews A, McGowan E, Rhodes R, Blanchard C, Culos-Reed S, Friedenreich $C$, et al. Identification and evaluation of the salient physical activity beliefs of colorectal cancer survivors. Cancer Nurs. 2013;37(1):14-22.

58. Morielli AR, Usmani N, Boulé NG, Severin D, Tankel K, Nijjar T, et al. Exercise motivation in rectal cancer patients during and after neoadjuvant 
chemoradiotherapy. Support Care Cancer. 2016;24:2919-26. https://doi.org/1 0.1007/s00520-016-3110-9.

59. Karlsson E, Dahl O, Rydwik E, Nygren-Bonnier M, Bergenmar M. Older patients' attitudes towards, and perceptions of, preoperative physical activity and exercise prior to colorectal cancer surgery-a gap between awareness and action. Support Care Cancer. 2020;28(8):3945-53. https://doi. org/10.1007/s00520-019-05237-7

60. Koutoukidis D, Beeken R, Lopes S, Knobf M, Lanceley A. Attitudes, challenges and needs about diet and physical activity in endometrial cancer survivors: a qualitative study. Eur J Cancer Care. 2016;26.

61. Trinh L, Plotnikoff R, Rhodes R, North S, Courneya K. Correlates of physical activity in population-based sample of kidney cancer survivors: an application of the theory of planned behavior. Int J Behav Nutr Phys Act. 2012;9(1):96. https://doi.org/10.1186/1479-5868-9-96.

62. Bryant A, Walton AML, Pergolotti M, Phillips B, Bailey C, Mayer D, et al. Perceived benefits and barriers to exercise for recently treated adults with acute leukemia. Oncol Nurs Forum. 2017;44(4):413-20. https://doi.org/10.11 88/17.ONF.413-420.

63. Granger C, Parry S, Edbrooke L, Abo S, Leggett N, Dwyer M, et al. Improving the delivery of physical activity services in lung cancer: a qualitative representation of the patient's perspective. Eur J Cancer Care. 2018;28(1): e12946. https://doi.org/10.1111/ecc.12946.

64. Missel M, Pedersen JH, Hendriksen C, Tewes M, Adamsen L. Exercise intervention for patients diagnosed with operable non-small cell lung cancer: a qualitative longitudinal feasibility study. Support Care Cancer. 2015;23(8):2311-8. https://doi.org/10.1007/s00520-014-2579-3.

65. Karvinen K, Vallance J, Walker P. Newly diagnosed lung cancer patients' preferences for and beliefs about physical activity prior to chemotherapy. Psychol Health Med. 2016;21(5):1-8. https://doi.org/10.1080/13548506.201 6.1139739.

66. Craike MJ, Hose K, Courneya KS, Harrison SJ, Livingston PM. Perceived benefits and barriers to exercise for recently treated patients with multiple myeloma: a qualitative study. BMC Cancer. 2013;13(1):319. https://doi.org/1 0.1186/1471-2407-13-319

67. Burnett PC, Gucciardi DF, Briffa NK. Perceptions of women diagnosed with ovarian cancer about exercise and urogynaecological and psychosexual outcomes—a qualitative study. Physiotherapy. 2015;101:e171-2. https://doi. org/10.1016/.jphysio.2015.03.326.

68. Craike MJ, Livingston PM, Botti M. An exploratory study of the factors that influence physical activity for prostate cancer survivors. Support Care Cancer. 2011;19(7):1019-28. https://doi.org/10.1007/s00520-010-0929-3.

69. Dennett AM, Harding KE, Reed MS. The challenge of timing: a qualitative study on clinician and patient perspectives about implementing exercisebased rehabilitation in an acute cancer treatment setting. Support Care Cancer. 2020;28(12):6035-43. https://doi.org/10.1007/s00520-020-05436-7.

70. Ferri A, Gane E, Smith M, Pinkham E, Gomersall S, Johnston V. Experiences of people with cancer who have participated in a hospital-based exercise program: a qualitative study. Support Care Cancer. 2020;29(3):1575-83. https://doi.org/10.1007/s00520-020-05647-y.

71. Mizrahi D, Wakefield CE, Simar D, Ha L, McBride J, Field P, et al. Barriers and enablers to physical activity and aerobic fitness deficits among childhood cancer survivors. Pediatr Blood Cancer. 2020;67(7):e28339. https://doi.org/1 $0.1002 / \mathrm{pbc} .28339$

72. Peeters C, Stewart A, Segal R, Wouterloot E, Scott CG, Aubry T. Evaluation of a cancer exercise program: patient and physician beliefs. Psychooncology. 2009;18(8):898-902. https://doi.org/10.1002/pon.1406.

73. Liska TM, Kolen AM. The role of physical activity in cancer survivors' quality of life. Health Qual Life Outcomes. 2020;18(1):197. https://doi.org/10.1186/ s12955-020-01448-3.

74. Catt S, Harder H, Sheward J, Sheward E, Fallowfield L. Exercise levels and experiences of those attending CUFITTER-a tailored exercise programme for people in cancer recovery. 2017. https://shore-c.sussex.ac.uk/posters/ CUFITTER\%20BPOS\%20poster\%202017\%20V3.pdf.

75. Catt S, Sheward J, Sheward E, Harder H. Cancer survivors' experiences of a community-based cancer-specific exercise programme: results of an exploratory survey. Support Care Cancer. 2018;26(9):3209-16. https://doi. org/10.1007/s00520-018-4179-0.

76. Höh J-C, Schmidt T, Hübner J. Physical activity among cancer survivors - what is their perception and experience? Support Care Cancer. 2018;26:1471-8. https://doi.org/10.1007/s00520-017-3977-0.
77. Cantwell M, Walsh D, Furlong B, Loughney L, Mccaffrey N, Moyna N, et al. Physical activity across the cancer journey: experiences and recommendations from people living with and beyond cancer. Phys Ther. 2020;100(5_suppl):162. https://doi.org/10.1200/JCO.2017.35.5_suppl.162.

78. Avancini A, Skroce K, Tregnago D, Frada P, Trestini I, Cercato MC, et al. "Running with cancer": a qualitative study to evaluate barriers and motivations in running for female oncological patients. PLoS One. 2020; 15(4):e0227846. https://doi.org/10.1371/journal.pone.0227846.

79. Groeneveld I, Boer A, Frings-Dresen M. Physical exercise and return to work: Cancer survivors' experiences. J Cancer Surviv. 2013;7(2):237-46. https://doi. org/10.1007/s11764-012-0264-4.

80. Mikkelsen HE, Vassbakk-Brovold K, Antonsen A, Berntsen S, Kersten C, Fegran L. Cancer patients' long-term experiences of participating in a comprehensive lifestyle intervention study while receiving chemotherapy. Cancer Nurs. 2020;43:1.

81. Cummins C, Kayes NM, Reeve J, Smith G, MacLeod R, McPherson KM. Navigating physical activity engagement following a diagnosis of cancer: a qualitative exploration. Eur J Cancer Care. 2017;26(4):e12608. https://doi. org/10.1111/ecc.12608.

82. Hennessy EM, Stevinson C, Fox KR. Preliminary study of the lived experience of exercise for cancer survivors. Eur J Oncol Nurs. 2005;9(2):155-66. https:// doi.org/10.1016/j.ejon.2004.08.003.

83. Below N, Fisher A, Epstone S, Reynolds J, Pugh G. Young adult cancer survivors' experience of taking part in a 12-week exercise referral programme: a qualitative study of the Trekstock RENEW initiative. Support Care Cancer. 2020;29(5):2613-20. https://doi.org/10.1007/s00520-020-05746-w.

84. Blaney J, Lowe-Strong A, Rankin J, Campbell A, Allen J, Gracey J. The cancer rehabilitation journey: barriers to and facilitators of exercise among patients with cancer-related fatigue. Phys Ther. 2010;90(8):1135-47. https://doi.org/1 $0.2522 /$ ptj.20090278

85. Smaradottir A, Smith A, Borgert A, Oettel K. Are we on the same page? Patient and provider perceptions about exercise in cancer care: a focus group study. J Natl Compr Cancer Netw. 2017;15(5):588-94. https://doi.org/1 0.6004/jincen.2017.0061.

86. Wu Y, Yi J, McClellan J, Kim J, Tian T, Parsons B, et al. Barriers and facilitators of healthy diet and exercise among adolescent and young adult cancer survivors: implications for behavioral interventions. J Adolesc Young Adult Oncol. 2015;4(4):184-91. https://doi.org/10.1089/jayao.2015.0028.

87. Lowe S, Danielson B, Beaumont C, Watanabe S, Courneya K. Physical activity interests and preferences of cancer patients with brain metastases: a crosssectional survey. BMC Palliat Care. 2016;15(1):7. https://doi.org/10.1186/s12 904-016-0083-x.

88. Jones LW, Guill B, Keir ST, Carter K, Friedman HS, Bigner DD, et al. Exercise interest and preferences among patients diagnosed with primary brain cancer. Support Care Cancer. 2007;15(1):47-55. https://doi.org/10.1007/s0052 0-006-0096-8.

89. Vallance J, Lavallee C, Culos-Reed N, Trudeau M. Rural and small town breast cancer survivors' preferences for physical activity. Int J Behav Med. 2013;20(4):522-8. https://doi.org/10.1007/s12529-012-9264-z.

90. Bernardo L, Abt K, Ren D, Bender C. Self-reported exercise during breast Cancer treatment. Cancer Nurs. 2010;33(4):304-9. https://doi.org/10.1097/ NCC.0b013e3181cdce2c.

91. McGowan E, Speed-Andrews A, Blanchard C, Rhodes R, Friedenreich C, Culos-Reed S, et al. Physical activity preferences among a population-based sample of colorectal cancer survivors. Oncol Nurs Forum. 2013;40(1):44-52. https://doi.org/10.1188/13.ONF.44-52.

92. Agasi-Idenburg C, Koning-van Zuilen M, Westerman M, Punt C, Aaronson N, Stuiver M. "I am busy surviving" - views about physical exercise in older adults scheduled for colorectal cancer surgery. J Geriatr Oncol. 2019;11(3): 444-50.

93. Thorsen L, Kirkegaard C, Loge J, Kiserud C, Johansen M, Gjerset G, et al. Feasibility of a physical activity intervention during and shortly after chemotherapy for testicular cancer. BMC Res Notes. 2017;10(1):214. https:// doi.org/10.1186/s13104-017-2531-y.

94. Murnane A, Geary B, Milne D. The exercise programming preferences and activity levels of cancer patients undergoing radiotherapy treatment. Support Care Cancer. 2012;20(5):957-62. https://doi.org/10.1007/s00520011-1167-z.

95. Buentzel J, Kusterer I, Rudolph Y, Kubin T, Micke O, Hübner J. Cancer patients' knowledge and acceptance of physical activities for rehabilitation. 
In Vivo. 2017;31:1187-92. doi: https://doi.org/10.21873/invivo.11188, https:// doi.org/10.21873/invivo.11188.

96. Ross WL, Le A, Zheng DJ, Mitchell H-R, Rotatori J, Li F, et al. Physical activity barriers, preferences, and beliefs in childhood cancer patients. Support Care Cancer. 2018;26(7):2177-84. https://doi.org/10.1007/s00520-017-4041-9.

97. Courneya K, Mckenzie D, Reid R, Mackey J, Gelmon K, Friedenreich C, et al. Barriers to supervised exercise training in a randomized controlled trial of breast cancer patients receiving chemotherapy. Ann Behav Med. 2008;35(1): 116-22. https://doi.org/10.1007/s12160-007-9009-4.

98. Vassbakk-Brovold K, Antonsen A, Berntsen S, Kersten C, Fegran L. Experiences of patients with breast cancer of participating in a lifestyle intervention study while receiving adjuvant chemotherapy. Cancer Nurs. 2017;41:1.

99. Monteiro-Guerra F, Signorelli G, Rivera O, Zubiete E, Caulfield B. Breast cancer survivors' perspectives on motivational and personalization strategies in mobile app-based physical activity coaching interventions: a qualitative study. JMIR mHealth uHealth. 2020;8(9):e18867. https://doi.org/10.2196/ preprints. 18867.

100. Hefferon K, Murphy H, McLeod J, Mutrie N, Campbell A. Understanding barriers to exercise implementation 5-year post-breast cancer diagnosis: a large-scale qualitative study. Health Educ Res. 2013;28(5):843-56. https://doi. org/10.1093/her/cyt083.

101. Nielsen AM, Welch WA, Gavin KL, Cottrell AM, Solk P, Torre EA, et al. Preferences for mHealth physical activity interventions during chemotherapy for breast cancer: a qualitative evaluation. Support Care Cancer. 2020;28(4):1919-28. https://doi.org/10.1007/s00520-019-05002-w.

102. Courneya K, Friedenreich C, Quinney H, Fields A, Jones L, Vallance J, et al. A longitudinal study of exercise barriers in colorectal cancer survivors participating in a randomized controlled trial. Ann Behav Med. 2005;29(2): 147-53. https://doi.org/10.1207/s15324796abm2902_9.

103. Romero-Elías M, Beltrán-Carrillo VJ, González-Cutre D, Jiménez-Loaisa A. Barriers to physical activity participation in colorectal cancer patients during chemotherapy treatment: a qualitative study. Eur J Oncol Nurs. 2020;46: 101769. https://doi.org/10.1016/j.jon.2020.101769.

104. Ray A, Twarozek A, Williams B, Erwin D, Underwood Willie III, Mahoney M. Exercise in African American and white colorectal aancer survivors: a mixedmethods approach. Rehabil Oncol. 2018;36(4):1-197. https://doi.org/10.1097/ 01.REO.0000000000000125.

105. Mas S, Quantin X, Ninot G. Barriers to, and facilitators of physical activity in patients receiving chemotherapy for lung cancer: an exploratory study. J Palliat Care. 2015;31(2):89-96. https://doi.org/10.1177/082585971503100204.

106. Evans O, Rose B, Cave J, Calman L. Fatigue and physical activity in lung cancer patients treated with immunotherapy: a mixed methods study. Psychooncology. 2020;29:22.

107. Sun V, Raz D, Kim J, Melstrom L, Hite S, Varatkar G, et al. Barriers and facilitators of adherence to a perioperative physical activity intervention for older adults with cancer and their family caregivers. J Geriatr Oncol. 2019; 11(2):256-62.

108. Kimball B, Nortey Asiedu GB, Thompson C. Building a healthy body after cancer: Young adult lymphoma survivors' perspectives on exercise after cancer treatment. J Adolesc Young Adult Oncol. 2017;7(2):217-29.

109. Mizrahi D, Broderick C, Samara J, Ryan M, Friedlander M. Physical activity in women with ovarian cancer: investigating the barriers and feasibility of exercise. Int J Gynecol Cancer. 2015;25(4):577-83. https://doi.org/10.1097/ IGC.0000000000000349.

110. Mizrahi D, Naumann F, Broderick C, Samara J, Ryan M, Friedlander M. Quantifying physical activity and the associated barriers for women with ovarian cancer. Int J Gynecol Cancer. 2015;25:577-83.

111. Zhang X, McClean D, Ko E, Morgan M, Schmitz K. Exercise among women with ovarian cancer: a feasibility and pre-/post-test exploratory pilot study. Oncol Nurs Forum. 2017;44(3):366-74. https://doi.org/10.1188/17.ONF.366-374.

112. Keogh J, Patel A, MacLeod R, Masters J. Perceived barriers and facilitators to physical activity in men with prostate cancer: possible influence of androgen deprivation therapy. Eur J Cancer Care. 2013;23(2):263-73. https:// doi.org/10.1111/ecc.12141.

113. Hackshaw-McGeagh L, Sutton E, Persad R, Aning J, Bahl A, Koupparis A, et al. Acceptability of dietary and physical activity lifestyle modification for men following radiotherapy or radical prostatectomy for localised prostate cancer: a qualitative investigation. BMC Urol. 2017;17(1):94. https://doi.org/1 0.1186/s12894-017-0284-5.
114. Dewhurst S, Tigue R, Sandsund C, Mein G, Shaw C. Factors influencing people's ability to maintain their activity levels during treatment for soft tissue sarcoma-a qualitative study. Physiotherapy. 2017;103:e141.

115. Dewhurst S, Tique R, Sandsund C, Mein G, Shaw C. Factors influencing people's ability to maintain their activity levels during treatment for soft tissue sarcoma - a qualitative study. Physiother Theory Pract. 2020;36(8): 923-32. https://doi.org/10.1080/09593985.2018.1519622.

116. Farrokhzadi L, Dhillon H, Goumas C, Young J, Cust A. Physical activity correlates, barriers, and preferences for women with gynecological cancer. Int J Gynecol Cancer. 2016;26(8):1530-7. https://doi.org/10.1097/IGC. 0000000000000790.

117. Grimshaw SL, Taylor NF, Mechinaud F, Conyers R, Shields N. Physical activity for children undergoing acute cancer treatment: a qualitative study of parental perspectives. Pediatr Blood Cancer. 2020;67(6):e28264. https://doi. org/10.1002/pbc.28264.

118. Adamsen L, Andersen C, Lillelund C, Bloomquist K, Møller T. Rethinking exercise identity: a qualitative study of physically inactive cancer patients' transforming process while undergoing chemotherapy. BMJ Open. 2017; 7(8):e016689. https://doi.org/10.1136/bmjopen-2017-016689.

119. Yang D, Hausien O, Aqeel M, Klonis A, Foster J, Renshaw D, et al. Physical activity levels and barriers to exercise referral among patients with cancer. Patient Educ Couns. 2017;100(7):1402-7. https://doi.org/10.1016/j.pec.2017. 01.019.

120. Ottenbacher A, Day R, Taylor W, Sharma S, Sloane R, Snyder D, et al. Exercise among breast and prostate cancer survivors - what are their barriers? J Cancer Surviv. 2011;5(4):413-9. https://doi.org/10.1007/s11764011-0184-8.

121. Bluethmann SM, Foo W, Winkels RM, Mama SK, Schmitz KH. Physical activity in older cancer survivors: what role do multimorbidity and perceived disability play? J Aging Phys Act. 2019;28(2):311-9. https://doi.org/10.1123/ja pa.2019-0086

122. Shoaf $L D$, Hilton AL, Patel RH. Perceived barriers and facilitators to exercise during and subsequent to cancer treatment in cancer survivors. Rehabil Oncol. 2020;38:E21.

123. Enblom A, Lindquist H, Bergmark K. Participation in water-exercising longterm after breast cancer surgery: experiences of significant factors for continuing exercising as a part of cancer rehabilitation. Eur J Cancer Care. 2017;27(1):e12736. https://doi.org/10.1111/ecc.12736.

124. Larsson IL, Jönsson C, Olsson AC, Gard G, Johansson K. Women's experience of physical activity following breast cancer treatment. Scand J Caring Sci. 2008;22(3):422-9. https://doi.org/10.1111/j.1471-6712.2007.00546.x.

125. Nock N, Owusu C, Flocke S, Krejci S, Kullman E, Austin K, et al. A community-based exercise and support group program improves quality of life in African-American breast cancer survivors: A quantitative and qualitative analysis. Int J Sport Exerc Med. 2015;1. https://doi.org/10.2393 7/2469-5718/1510020.

126. Narayanan V, Koshy C. Fatigue in cancer: a review of literature. Indian J Palliat Care. 2009;15(1):19-25. https://doi.org/10.4103/0973-1075.53507.

127. Cramp F, Byron-Daniel J. Exercise for the management of cancer-related fatigue in adults. Cochrane Database Syst Rev. 2012;11:CD006145.

128. IJsbrandy C, Harten W, Gerritsen W, Hermens R, Ottevanger P. Healthcare professionals' perspectives of barriers and facilitators in implementing physical activity programmes delivered to cancer survivors in a shared-care model: a qualitative study. Support Care Cancer. 2020;28(7):3429-40. https:// doi.org/10.1007/s00520-019-05108-1.

129. Richardson EV, Smith B, Papathomas A. Disability and the gym: experiences, barriers and facilitators of gym use for individuals with physical disabilities. Disabil Rehabil. 2017;39(19):1950-7. https://doi.org/10.1080/09638288.201 6.1213893.

130. Rimmer J, Padalabalanarayanan S, Malone L, Mehta T. Fitness facilities still lack accessibility for people with disabilities. Disabil Health J. 2016;10:21421.

131. Calder A, Sole G, Mulligan $H$. The accessibility of fitness centers for people with disabilities: a systematic review. Disabil Health J. 2018;11(4):525-36. https://doi.org/10.1016/j.dhjo.2018.04.002.

\section{Publisher's Note}

Springer Nature remains neutral with regard to jurisdictional claims in published maps and institutional affiliations. 